\title{
Ephexin1 Is Required for Eph-Mediated Limb Trajectory of Spinal Motor Axons
}

\author{
Chih-Ju Chang, ${ }^{1,2,3 *}$ Ming-Yuan Chang, 4,5* Szu-Yi Chou, ${ }^{5,6}{ }^{\circ}$ Chi-Chen Huang, ${ }^{5,6}$ Jian-Ying Chuang, 5,6 @ Tsung-I Hsu, ${ }^{7}$

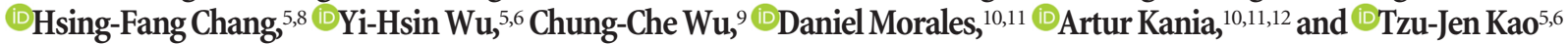 \\ ${ }^{1}$ Department of Neurosurgery, Cathay General Hospital, Taipei 110, Taiwan, ${ }^{2}$ School of Medicine, Fu Jen Catholic University, New Taipei 242 , Taiwan, \\ ${ }^{3}$ Department of Mechanical Engineering, National Central University, Taoyuan 320, Taiwan, ${ }^{4}$ Division of Neurosurgery, Department of Surgery, Min-Sheng \\ General Hospital, Taoyuan 330, Taiwan, ${ }^{5}$ Graduate Institute of Neural Regenerative Medicine, College of Medical Science and Technology, ${ }^{6}$ Technology and \\ Center for Neurotrauma and Neuroregeneration, ${ }^{7}$ Center for Neurotrauma and Neuroregeneration, ${ }^{8}$ School of Public Health, ${ }^{9}$ Department of Neurosurgery, \\ Taipei Medical University Hospital, Taipei Medical University, Taipei 110, Taiwan, ${ }^{10}$ Institut de recherches cliniques de Montréal, Montréal, Quebec H2W \\ 1R7, Canada, ${ }^{11}$ Integrated Program in Neuroscience and ${ }^{12}$ Department of Anatomy and Cell Biology, Division of Experimental Medicine, McGill University, \\ Montréal, Quebec H3A 2B2, Canada
}

The precise assembly of a functional nervous system relies on the guided migration of axonal growth cones, which is made possible by signals transmitted to the cytoskeleton by cell surface-expressed guidance receptors. We investigated the function of ephexin1, a Rho guanine nucleotide exchange factor, as an essential growth-cone guidance intermediary in the context of spinal lateral motor column (LMC) motor axon trajectory selection in the limb mesenchyme. Using in situ mRNA detection, we first show that ephexin1 is expressed in LMC neurons of chick and mouse embryos at the time of spinal motor axon extension into the limb. Ephexin1 loss of function and gain of function using in ovo electroporation in chick LMC neurons, of either sex, perturbed LMC axon trajectory selection, demonstrating an essential role of ephexin 1 in motor axon guidance. In addition, ephexin 1 loss in mice of either sex led to LMC axon trajectory selection errors. We also show that ephexin 1 knockdown attenuates the growth preference of LMC neurites against ephrins in vitro and Eph receptor-mediated retargeting of LMC axons in vivo, suggesting that ephexin1 is required in Eph-mediated LMC motor axon guidance. Finally, both ephexin1 knockdown and ectopic expression of nonphosphorylatable ephexin1 mutant attenuated the retargeting of LMC axons caused by Src overexpression, implicating ephexin1 as an Src target in Eph signal relay in this context. In summary, our findings demonstrate that ephexinl is essential for motor axon guidance and suggest an important role in relaying ephrin:Eph signals that mediate motor axon trajectory selection.

Key words: axon guidance; motor neuron; spinal cord

\section{Significance Statement}

The proper development of functioning neural circuits requires precise nerve connections among neurons or between neurons and their muscle targets. The Eph tyrosine kinase receptors expressed in neurons are important in many contexts during neuralcircuit formation, such as axon outgrowth, axon guidance, and synaptic formation, and have been suggested to be involved in neurodegenerative disorders, including amyotrophic lateral sclerosis and Alzheimer's disease. To dissect the mechanism of Eph signal relay, we studied ephexin1 gain of function and loss of function and found ephexin1 essential for the development of limb nerves toward their muscle targets, concluding that it functions as an intermediary to relay Eph signaling in this context. Our work could thus shed new light on the molecular mechanisms controlling neuromuscular connectivity during embryonic development.

\section{Introduction}

The precise assembly of a functional nervous system requires the guided migration of axonal growth cones, which is made possible

Received Aug. 9, 2017; revised Jan. 10, 2018; accepted Jan. 15, 2018.

Author contributions: C.-J.C., M.-Y.C., and T.-J.K. designed research; M.-Y.C., T.-I.H., H.-F.C., Y.-H.W., and D.M. performed research; S.-Y.C., C.-C.H., J.-Y.C., C.-C.W., and A.K. contributed unpublished reagents/analytic tools; C.-J.C., M.-Y.C., D.M., and T.-J.K. analyzed data; M.-Y.C. and T.-J.K. wrote the paper.

This work was supported by the Ministry of Science and Technology, Taiwan (MOST 105-2628-B-038-004-MY3) and the Cathay General Hospital (103CGH-TMU-04). We thank Meirong Liang for technical support, and Charlene Chao for secretarial assistance. by signals transmitted to the cytoskeleton by cell surfaceexpressed guidance receptors. Ephexin 1 has been proposed to be involved in this process (Shamah et al., 2001, Sahin et al., 2005), thus prompting us to determine its function in the guidance of spinal motor axons into the limb mesenchyme.

${ }^{*}$ C.-J.C. and M.-Y.C. contributed equally to this work.

The authors declare no competing financial interests.

Correspondence should be addressed to Tzu-Jen Kao at the above address. E-mail: geokao@tmu.edu.tw.

DOI:10.1523/JNEUROSCI.2257-17.2018

Copyright $\odot 2018$ the authors $\quad 0270-6474 / 18 / 382043-14 \$ 15.00 / 0$ 
Ephexin 1 is a member of the Dbl family of guanine nucleotide exchange factors (GEFs) for Rho family GTPases and is highly expressed in the CNS during development (Shamah et al., 2001). Ephexin1 has been proposed to mediate many physiological events, including dendritic spine development, synapse remodeling, and growth-cone collapse (Sahin et al., 2005; Fu et al., 2007; Frank et al., 2009; Shi et al., 2010). Initial studies of ephexin1 function in axon guidance focused on in vitro experiments demonstrating ephexin1 involvement in EphA-mediated growthcone guidance in cultured retinal ganglion cells (RGCs; Shamah et al., 2001; Knöll and Drescher, 2004) and in vivo findings showing ephexin1-mediated early axon repulsion in motor neurons (Sahin et al., 2005). However, researchers still need to clarify in vivo the underlying mechanism of ephexin1-mediated axon guidance events as well as the essential functions of ephexin1 in axon guidance, including (1) its role as a signaling intermediary downstream of EphA versus EphB tyrosine kinase receptors and (2) its involvement in other signaling systems.

A simple neuronal circuit suited for the study of axon guidance signaling is the axon trajectories of spinal motor neurons that innervate limb muscles and reside in the lateral motor column (LMC) of the spinal cord (Tosney and Landmesser, 1985). LMC neurons are organized myotopically: the lateral divisions of LMC neurons invariantly innervate dorsal limb muscles, while the medial divisions of LMC neurons innervate ventral limb muscles (Landmesser, 1978; Lance-Jones and Landmesser, 1981). Lateral and medial LMC motor neurons express LIM homeodomain transcription factors Lim1 and Isl1, which control LMC axonal trajectories in part by restricting the expression of EphA4 and EphB1 receptors to lateral and medial LMC axons, respectively. Their ligands, ephrins, are expressed in ventral (ephrin-As) or dorsal (ephrin-Bs) limb mesenchyme, and repulsive ephrin: Eph signaling has been proposed to mediate the proper selection of limb nerve trajectory (Tsuchida et al., 1994; Helmbacher et al., 2000; Eberhart et al., 2002; Kania and Jessell, 2003; Luria et al., 2008). Recent evidence suggests that netrin-1 expressed in the limb and its receptors Unc5c and Dcc in both divisions of LMC neurons also contribute along with Eph signaling to the guidance of these axons (Poliak et al., 2015). This simple binary choice of LMC axons is thus an ideal in vivo system to study the molecular cascade downstream of axon guidance receptors.

Here we first show that ephexin 1 is expressed in LMC neurons during motor axon outgrowth in the limb. Ephexin1 loss of function and gain of function perturb LMC axon trajectory selection with opposite effects. We also show that ephexinl knockdown attenuates the growth preference of LMC neurites against ephrins in vitro and Eph receptor-mediated and Src-mediated redirections of LMC axons in vivo. Combined, these results demonstrate that ephexin1 functions as an essential signaling intermediary downstream of Src in ephrin:Eph-mediated LMC axon trajectory selection.

\section{Materials and Methods}

Animals. Fertilized chick eggs (Animal Health Research Institute, Council of Agriculture, Executive Yuan, Taiwan) were stored for $\leq 1$ week at $18^{\circ} \mathrm{C}$, incubated at $38^{\circ} \mathrm{C}$, and staged according to standard protocols (Hamburger and Hamilton, 1951). All mice were housed in an airconditioned vivarium with ad libitum access to food and water and $\mathrm{a} 12 \mathrm{~h}$ light/dark cycle. All protocols of handling animals, including chick and mouse embryos, were approved by the Institutional Animal Care and Use Committee at Taipei Medical University, Taipei, Taiwan.

Molecular biology. The characterization of expression constructs, including e[Isl1]::GFP, EphA4::GFP, EphB2::GFP, and ephexin1 has been described (Kania and Jessell, 2003; Knöll and Drescher, 2004; Zhou et al., 2007; Kao et al., 2009).

In situ hybridization cDNA probes were prepared as described previously (Kao et al., 2009). In brief, target sequence amplification primers were designed using Primer3 version 0.4.0 software (Rozen and Skaletsky, 2000) and the probe size was set between 600 and $800 \mathrm{bp}$. One-step RT-PCR was performed (Qiagen) using the designed primers containing T7 polymerase promoters (Invitrogen) to make an amplified cDNA template from chick Hamburger-Hamilton (HH) stage 25/26 or mouse embryonic day (E) 11.5 pooled brain RNA. The PCR product was purified by gel electrophoresis in $1 \%$ agarose gel and gel extraction using QIAquick gel extraction kit (Qiagen). The purified DNA was then reamplified by PCR. The yield of DNA was estimated by the Low DNA Mass Ladder (Invitrogen) after gel electrophoresis. DIG-labeled RNA probes were synthesized by in vitro transcription with T7 RNA polymerase using a DIG RNA labeling kit (Roche). All probes were verified by sequencing. The source of sequence and the recognized region for each probe are described as follows: chick ephexin1, NM_001010841, 2215-2915; mouse ephexin1, NM_001111314, 1966-2665. The details of Isl1 and Lim1 probes have been described previously (Tsuchida et al., 1994).

Chick in ovo electroporation. Spinal cord electroporation of expression plasmids was performed at $\mathrm{HH}$ stage $18 / 19$, of either sex, as described previously (Momose et al., 1999; Luria et al., 2008; Kao et al., 2009). In brief, a 5-8 $\mu \mathrm{g} / \mu$ l solution of plasmid DNA in TE buffer, pH 7.5 (10 mM Tris- $\mathrm{HCl}$ and $1 \mathrm{~mm}$ EDTA; Invitrogen) was injected into the lumbar neural tube through a small eggshell window under a stereomicroscope (Sage Vision Technology). Lower bodies of chick embryos were then electroporated with platinum/iridium electrodes (FHC) and the Ovodyne TSS20 electroporator (Abbotsbury Engineering; settings: $30 \mathrm{~V}, 5$ pulses, $50 \mathrm{~ms}$ wide in a $1 \mathrm{~s}$ interval). Shell windows were sealed with Parafilm (Pechinery Plastic Packaging) and incubated at $38^{\circ} \mathrm{C}$ until harvesting at $\mathrm{HH}$ stage $28 / 29$. The efficiency of electroporation varied between 5 and $30 \%$ of total LMC neurons electroporated, depending upon the size of construct and DNA concentration used. When untagged expression plasmids were electroporated with GFP expression plasmids or other plasmids fused with GFP, their concentration was at $\geq 3$ times that of GFP-fused plasmids to ensure high efficiency of coexpression. siRNA duplex oligonucleotides with $3^{\prime}$ TT overhang were purified over MicroSpin G-25 columns (GE Healthcare) in TE buffer with $20 \mathrm{~mm} \mathrm{NaCl}$ (Sigma-Aldrich). One microgram per microliter of GFP expression plasmid was coelectroporated with the siRNA solution to label motor axons. siRNA sequences (sense strand) are as follows: [ephexin1]siRNA, 1:1 mixture of CCTTCCTGATTCTGCCATT and GCACATAAGGAGCTGGAAA; scrambled [ephexin1]siRNA, 1:1 mixture of CCTGTCTTAGTCCCTCATT and GCAGAATCGAGGGTACAAA.

HRP retrograde labeling of LMC motor neurons. Retrograde labeling of mouse motor neurons was performed as described previously (Luria et al., 2008; Poliak et al., 2015). In brief, E12.5 embryos of either sex were dissected at thoracic level and incubated in aerated DMEM/F12 medium (Invitrogen) at room temperature. The retrograde tracer used was a $20 \%$ solution of HRP (Roche) made by dissolving $100 \mathrm{mg}$ of HRP in $450 \mu \mathrm{l}$ of PBS with $50 \mu$ l of $10 \%$ lysophosphatidylcholine (Fluka) in PBS. The HRP solution was injected into either the dorsal or ventral forelimb proximal muscle group and embryos were incubated at $32^{\circ} \mathrm{C}$ under an infrared lamp and aerated with $95 \%$ air and $5 \% \mathrm{CO}_{2}$. Fresh medium was added every $30 \mathrm{~min}$ for $5 \mathrm{~h}$.

In vitro stripe assay. Protein carpets were made using silicon matrices with a channel system as described previously (Knöll et al., 2007). Carpets contained an alternating stripe pattern deposited in the following order: the first stripe contained a mixture of ephrin-Fc (or netrin-1) and Fc-specific Cy3 conjugated (4:1 weight ratio) while the second stripe contained only Fc reagents without Fc-specific Cy3 conjugated. E5 chick spinal motor columns were dissected and collected as described previously (Gallarda et al., 2008; Kao and Kania, 2011). In brief, E5 chick embryos of either sex were collected in ice-cold motor neuron medium [Neurobasal (Invitrogen), B-27 supplement (1:50, Invitrogen), $0.5 \mathrm{~mm}$ L-glutamate (Sigma-Aldrich), $25 \mathrm{~mm} \mathrm{L-glutamine} \mathrm{(Invitrogen),} \mathrm{and}$ penicillin-streptomycin (1:100; Wisent)]. The lumbar spinal cord was opened at the dorsal midline to allow the excision of motor columns 
under a stereomicroscope. Spinal motor columns were recognizable as the bulge part of the open-book spinal cord. Sharp tungsten needles (World Precision Instruments) were used to remove the dorsal spinal cord at the lateral part and the floor plate and the medial motor column at the middle part of the open-book spinal cord. The excised motor column was then trimmed into square-shaped explants with $\sim 1 / 4$ width of motor column. Ten to 20 explants were then plated on lamininprecoated ( $20 \mu \mathrm{g} / \mathrm{ml}$; Invitrogen) $60 \mathrm{~mm}$ tissue culture dishes (Sarstedt) containing different combinations of stripe carpets in motor neuron medium and incubated in an atmosphere of $95 \%$ air and $5 \% \mathrm{CO}_{2}$ at $37^{\circ} \mathrm{C}$ for $18 \mathrm{~h}$.

In situ mRNA detection and immunostaining. Chick and mouse embryos were fixed in a $4 \%$ solution of paraformaldehyde (Sigma-Aldrich) in PBS, equilibrated with $30 \%$ sucrose in PBS, embedded in O.C.T. (Sakura Finetek), and stored at $-80^{\circ} \mathrm{C}$. Twelve micrometer sections were collected using a cryostat microtome (Leica).

In situ mRNA detection was performed as described previously (Schaeren-Wiemers and Gerfin-Moser, 1993; Kania and Jessell, 2003). In brief, tissue sections were first fixed in $4 \%$ solution of paraformaldehyde in PBS for $10 \mathrm{~min}$ at room temperature, washed three times with PBS, and digested in Proteinase K solution $[1 \mu \mathrm{g} / \mathrm{ml}$ Proteinase $\mathrm{K}$ (Roche) in $6.25 \mathrm{~mm}$ EDTA, pH 8.0, and $50 \mathrm{~mm}$ Tris, pH 7.5 (Invitrogen)]. Samples were acetylated for $10 \mathrm{~min}$ by immersion in a mixture of $6 \mathrm{ml}$ of triethanolamine (Sigma-Aldrich), $500 \mathrm{ml}$ of double-distilled $\mathrm{H}_{2} \mathrm{O}$, and $1.30 \mathrm{ml}$ of acetic anhydride (Sigma-Aldrich). After PBS washes, samples were incubated with hybridization buffer [50\% formamide, $5 \times$ SSC $(0.75 \mathrm{M}$ $\mathrm{NaCl}, 0.075 \mathrm{M} \mathrm{NaAc}$ ), $5 \times$ Denhardt's solution (Sigma-Aldrich) and 500 $\mu \mathrm{g} / \mathrm{ml}$ salmon sperm DNA (Roche)] for $2 \mathrm{~h}$ at room temperature followed by incubation overnight at $72^{\circ} \mathrm{C}$ with DIG-labeled RNA probes (see above) in the hybridization buffer at a concentration of $2-5 \mathrm{ng} / \mu \mathrm{l}$. After hybridization, samples were immersed in $5 \times \mathrm{SSC}$ at $72^{\circ} \mathrm{C}$, followed by two washes in $0.2 \times \mathrm{SSC}$ at $72^{\circ} \mathrm{C}$ for $45 \mathrm{~min}$ each and $0.2 \times \mathrm{SSC}$ at room temperature for $5 \mathrm{~min}$. Tissues were then rinsed with B1 buffer $(0.1 \mathrm{M}$ Tris, $\mathrm{pH} 7.5$, and $0.15 \mathrm{M} \mathrm{NaCl})$ for 5 min, blocked with B2 buffer $(10 \%$ heat-inactivated horse serum in B1) for $1 \mathrm{~h}$ at room temperature, and incubated with anti-DIG antibody (1:5000 in B2; Roche) overnight at $4^{\circ} \mathrm{C}$. Samples were then rinsed with $\mathrm{B} 1$ and equilibrated with $\mathrm{B} 3$ buffer (0.1 м Tris, $\mathrm{pH}$ 9.5, $0.1 \mathrm{~m} \mathrm{NaCl}, 0.05 \mathrm{M} \mathrm{MgCl}_{2}$ ). To detect bound anti-DIG antibodies, samples were incubated with B4 buffer $[100 \mathrm{mg} / \mathrm{ml} \mathrm{NBT,} 50$ $\mathrm{mg} / \mathrm{ml} \mathrm{BCIP}$ (Roche), and $400 \mathrm{~mm}$ levamisol (Sigma-Aldrich) in B3] in the dark. The reaction was stopped by immersion in $\mathrm{H}_{2} \mathrm{O}$.

Immunostaining was performed as described previously (Kao et al., 2009; Kao and Kania, 2011). In brief, sectioned tissue or cultured explants were washed in PBS, incubated in blocking buffer [ $1 \%$ heatinactivated horse serum in $0.1 \%$ Triton-X/PBS (Sigma-Aldrich)] for 5 min, followed by incubation overnight at $4^{\circ} \mathrm{C}$ in selected primary antibodies diluted in blocking solution. After the incubation in primary antibodies, samples were washed with PBS and incubated with appropriate secondary antibodies for $1 \mathrm{~h}$ at room temperature. See Table 1 for the list of antibodies used.

Image quantification. Images were acquired using a Leica DM6000 microscope or a EVOS FL microscope (Thermo Fisher Scientific). GFPlabeled axonal projections were quantified by combining over-threshold pixel counts in limb-section images containing limb nerves (10-15 limb sections with $12 \mu \mathrm{m}$ thickness each) using Photoshop (Adobe). The dorsal or ventral limb nerve was selected by gating on the neurofilament channel and using the Lasso Tool, and pixel counts from the threshold to the maximal level were those indicated in the Histogram window of the GFP channel. Motor neuron numbers were quantified by combining cell counts of a series of spinal cord section images (5-10 limb sections from each embryo) using Photoshop. Proportions of GFP-labeled or EphA4labeled neurites of cultured motor neuron explants growing on each stripe type were quantified by combining over-threshold pixel quantification over either first or second types of stripes in multiple images using Photoshop. To minimize possible experimental bias, multiple limb sections were selected every 2-3 sections anterioposteriorly until covering the entire crural plexus of limb nerves in each embryo, while cultured LMC explants were selected randomly for quantification. In addition, the proportions of total and electroporated motor neuron cell numbers were
Table 1. Antibodies and Fc reagents used

\begin{tabular}{llll}
\hline Antigen/pure protein & Source species & Dilution & Source/reference \\
\hline EphA4 & Rabbit & $1: 500$ & Santa Cruz Biotechnology \\
EphB1 & Goat & $1: 500$ & Santa Cruz Biotechnology \\
Ephexin1 & Rabbit & $1: 500$ & Abcam \\
& Mouse (2H3) & $1: 100$ & DSHB \\
Neurofilament & Mouse (3A10) & $1: 100$ & DSHB \\
Isl1/2 & Mouse & $1: 100$ & DSHB \\
Lim1/2 & Mouse & $1: 100$ & DSHB \\
HRP & Goat & $1: 2000$ & Roche \\
Foxp1 & Rabbit & $1: 1000$ & Abcam \\
GFP & Guinea pig & $1: 1000$ & AbD Serotec \\
GFP & Rabbit & $1 / 1000$ & Molecular Probes \\
Ephrin-A5-Fc & Human & $10 \mu \mathrm{g} / \mathrm{ml}$ & R\&D Systems \\
Ephrin-B2-Fc & Mouse & $10 \mu \mathrm{g} / \mathrm{ml}$ & R\&D Systems \\
Fc & Human & $10 \mu \mathrm{g} / \mathrm{ml}$ & R\&D Systems \\
Anti-Fc & Mouse & $1: 4 \mathrm{mass}$ ratio to ephrin & Sigma-Aldrich \\
\hline
\end{tabular}

quantified for most experimental groups to ensure little change of cell identity or abnormal cell death before the subsequent analysis of axon growth preferences (dorsal/ventral, medial/lateral, or first stripe/second stripe).

Statistical analysis. Data from the experimental replicate sets were evaluated using Microsoft Excel. Means of the combined proportions or cell numbers were compared using the Fisher's exact test for the proportions of medial/lateral LMC neurons in retrograde labeling experiments or Mann-Whitney $U$ test for the proportions of dorsal/ventral preference of limb nerves or cultured LMC neurites growing on first stripe/second stripe with the threshold for significance set at 0.05 (Poliak et al., 2015).

\section{Results}

\section{Ephexin1 expression in LMC motor neurons}

Previous studies have proposed a role of ephexin 1 in axon repulsion of RGCs and motor neurons (Shamah et al., 2001; Knöll and Drescher, 2004; Egea et al., 2005; Sahin et al., 2005). To further investigate ephexin 1 function in motor axon guidance in vivo and to define its role in specific axon guidance pathways involved in this context, we first determined whether ephexin 1 is expressed in LMC when motor axons grow into the limb mesenchyme, between $\mathrm{HH}$ stages 25 and 27 in chick embryos and between E10.5 and E11.5 in mouse embryos (Hamburger and Hamilton, 1951; Tosney and Landmesser, 1985; Kania et al., 2000). We thus checked ephexin1 expression in the lumbar spinal cord of $\mathrm{HH}$ stage 25/26 chick embryos and both brachial and lumbar spinal cord of E11.5 mouse embryos. Subpopulations of LMC neurons innervating the dorsal and ventral limb muscles were identified by the expression of the lateral LMC marker Lim1 and the medial LMC neuron marker Isl1 (Fig. $1 A, B, D, E, G, H$ ). Ephexin1 mRNA was found to be highly expressed in both lateral and medial LMC neurons in chick and mouse embryos (Fig. 1C,F,I). We also detected the expression of ephexin 1 protein in mouse LMC neurons (see Fig. 4D). No obvious difference in ephexin 1 expression levels was observed between medial and lateral LMCs in chick and mouse or between the brachial and lumbar spinal cords of the mouse embryos.

\section{Ephexin 1 is required for the selection of limb trajectory by LMC axons}

Previous studies have suggested a role for ephexin 1 in regulating LMC axon growth when spinal nerves just reach the base of the limb at HH stage 23 in chick embryos (Sahin et al., 2005). To test whether ephexin 1 functions in the selection of dorsal or ventral limb nerves by LMC axons, we knocked down ephexin 1 expres- 


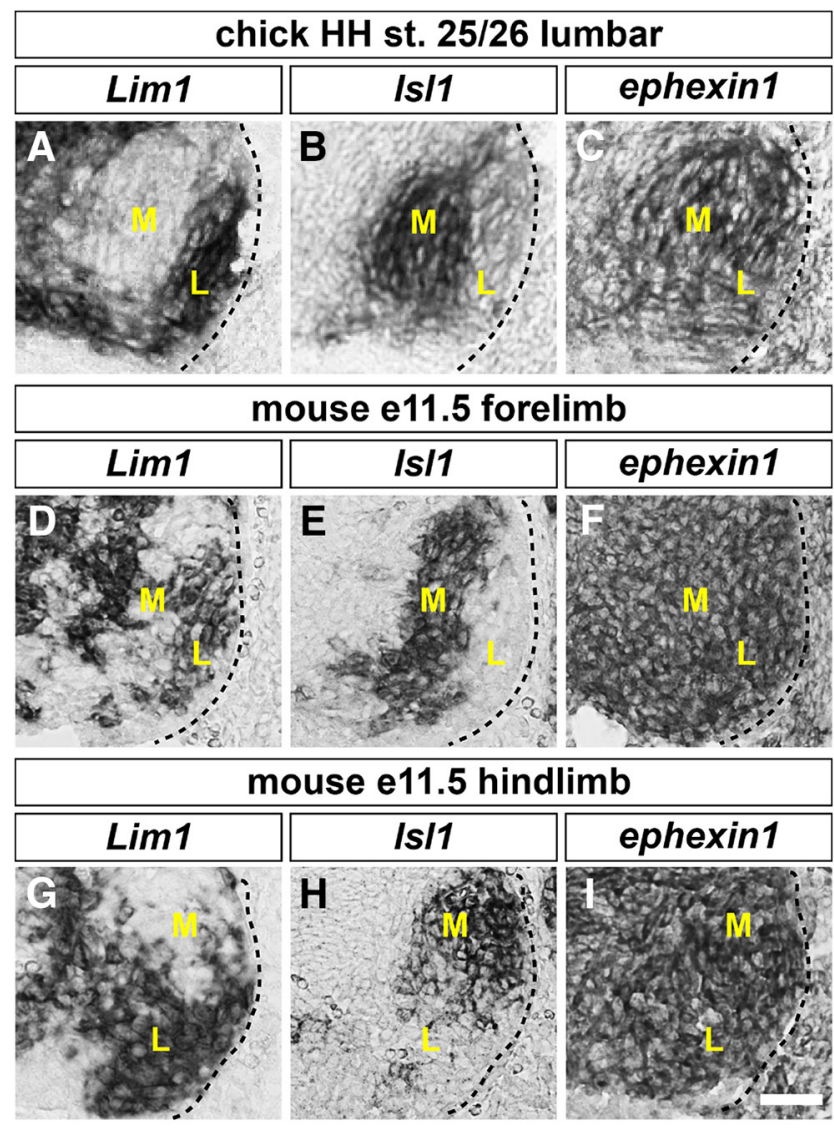

Figure 1. Expression of ephexin 1 in chick and mouse LMC motor neurons. A-I, Detection of mRNA in consecutive sections of spinal cords: all chick sections are HH stage 25/26 lumbar spinal cords; all mouse sections are E11.5 lumbar spinal cords. $\boldsymbol{A}, \boldsymbol{B}$, Detection of $\operatorname{Lim} 1(\boldsymbol{A})$ and $/ s / 1(\boldsymbol{B})$ mRNA in the chick spinal cord, highlighting lateral and medial LMC neurons, respectively. $C$, Detection of ephexin $1 \mathrm{mRNA}$ in both medial and lateral $L M C$ neurons. $\boldsymbol{D}, \boldsymbol{E}, \boldsymbol{G}, \boldsymbol{H}$, Detection of $\operatorname{Lim} 1(\boldsymbol{D}, \boldsymbol{G})$ and $/ s / 1(\boldsymbol{E}, \boldsymbol{H}) \mathrm{mRNA}$ in mouse LMC neurons. $\boldsymbol{F}$, I, Detection of ephexin $1 \mathrm{mRNA}$ in both medial and lateral mouse LMC neurons. M, Medial; L, lateral. Scale bar: (in I) $\boldsymbol{A}-\boldsymbol{I}, 30 \mu \mathrm{m}$.

sion by introducing inhibitory siRNA against ephexin1 mRNA ([ephexin1] siRNA) into LMC neurons. To do this, we coelectroporated siRNA with a GFP expression plasmid into the chick lumbar neural tube before LMC neuron specification and axon entry into the limb at $\mathrm{HH}$ stage $18 / 19$, and examined $\mathrm{GFP}^{+}$motor axons in dorsal and ventral divisional nerve branches exiting the crural plexus at HH stage 28/29 (Kania and Jessell, 2003). Coelectroporation of [ephexin1] siRNA and GFP plasmid significantly reduced ephexin1 mRNA expression compared with embryos electroporated with a control GFP plasmid or with scrambled [ephexin1] siRNA (Fig. $2 A-D ; p=5.25^{\star} 10^{-5}$ vs GFP, $p=8.62^{\star} 10^{-5}$ vs scrambled [ephexin1] siRNA; Table 2). In addition, it did not cause obvious changes in LMC neuron numbers expressing the marker Foxp1 nor did it change the proportions of lateral LMC (Foxp1 ${ }^{+}, \mathrm{Isl1}^{-}$) versus medial LMC (Foxp1 ${ }^{+}$, Isl1 ${ }^{-}$) neurons when compared with embryos electroporated with a control GFP plasmid or scrambled [ephexin1] siRNA (Fig. $2 G, H ; \quad p=0.5919$ vs GFP, $p=0.7707$ vs scrambled [ephexin1] siRNA for total Foxp $1^{+}$neuron numbers/section; $p=$ 0.1310 vs GFP, $p=0.5788$ vs scrambled [ephexin1] siRNA for the proportions of lateral or medial LMC neurons). Similar numbers of electroporated neurons were also shown in both LMC divisions when comparing groups coexpressing [ephexin1]siRNA and GFP with controls (Fig. 2I; $p=0.7284$ vs GFP, $p=0.1755$ vs scrambled [ephexin1] siRNA).
To determine whether ephexin 1 knockdown affects the choice of limb trajectory by LMC axons, we quantified the proportions of $\mathrm{GFP}^{+}$axons in the dorsal and ventral limb nerve branches by integrating fluorescence intensities of a series of hindlimb section images in multiple embryos for each experimental condition (Kania and Jessell, 2003; Luria et al., 2008). In embryos coelectroporated with [ephexin1]siRNA and GFP, a significantly higher proportion of $\mathrm{GFP}^{+}$axons were observed in the dorsal nerve branches when compared with both GFP or scrambled [ephexin1] siRNA controls (Fig. $2 J-L ; p=4.41^{\star} 10^{-4}$ vs GFP, $p=2.19^{\star} 10^{-4}$ vs scrambled [ephexin1]siRNA). This axon misrouting effect was rescued by mouse ephexin 1 coexpression (Fig. $2 L, N ; p=6.64^{\star} 10^{-5}$ ). These findings indicate that ephexinl knockdown causes a significantly greater proportion of LMC motor axons to enter the dorsal limb.

We then performed gain-of-ephexin1-function experiments by coelectroporating ephexin 1 and GFP expression plasmids into LMC neurons and analyzed motor axon trajectories in the limb. The specification and survival of LMC neurons were normal in embryos expressing both ephexin1 and GFP compared with GFP controls (Fig. $2 E-H ; p=0.6486$ for total Foxp ${ }^{+}$neuron numbers/section; $p=0.1012$ for the proportions of lateral or medial LMC neurons), and $\mathrm{GFP}^{+}$LMC neurons indicated similar amounts of electroporated cells in both LMC divisions (Fig. $2 E, F, I ; p=0.4302$ ). In embryos expressing both ephexin 1 and $G F P$, a significantly higher proportion of $\mathrm{GFP}^{+}$axons was observed in ventral nerves when compared with GFP controls (Fig. $\left.2 J, M ; p=9.33^{\star} 10^{-4}\right)$, suggesting that ephexin 1 overexpression causes a significantly greater proportion of LMC motor axons to enter the ventral limb. Together, these findings demonstrate that ephexin1 expressed by LMC motor neurons is essential for the fidelity of LMC axon guidance in the limb.

Two possible scenarios could explain the increased proportion of LMC neurons projecting into the dorsal nerve branch following ephexin1 knockdown: (1) some medial LMC axons enter the dorsal limb nerve, or (2) both medial and lateral LMC axons project into both limb nerves, but with a greater proportion of medial LMC axons projecting into the dorsal limb nerve. In either case, we expected a loss of fidelity of medial LMC trajectory selection caused by ephexin1 knockdown. To determine whether ephexinl knockdown results in redirection of medial LMC axons into the dorsal limb mesenchyme, we coelectroporated [ephexin1]siRNA with the e[Isl1]::GFP plasmid, which preferentially labels medial LMC motor neurons and their axons (Kao et al., 2009). In controls, we electroporated the $e[I s l 1]:: G F P$ plasmid only. In embryos coelectroporated with [ephexin1]siRNA and with the e[Isl1]::GFP, a significantly higher proportion of $\mathrm{GFP}^{+}$axons was observed in the dorsal limb nerve when compared with $e[I s l 1]:: G F P$-electroporated controls (Fig. $2 N, O ; p=1.51^{\star} 10^{-4}$ ). These findings indicate that ephexin1 is required for the fidelity of limb trajectory selection by medial LMC axons.

The $\mathrm{GFP}^{+}$axon-counting experiments do not allow us to compare the extent to which both medial and lateral divisions are sensitive to ephexin1 loss of function. To determine whether ephexin 1 function is required for the selection of appropriate LMC axon trajectory, we labeled LMC neurons by HRP retrograde tracer injection into the dorsal or ventral shank muscles of HH stage 28/29 embryos electroporated with [ephexin1]siRNA and GFP expression plasmids or with GFP alone, and determined the LMC divisional identity of labeled neurons (Kania and Jessell, 2003; Kao et al., 2009). The proportion of electroporated medial LMC neurons labeled by dorsal limb HRP injections was significantly higher in ephexin1-knockdown embryos when compared with controls, indicating that ephexin1 is required for the choice 

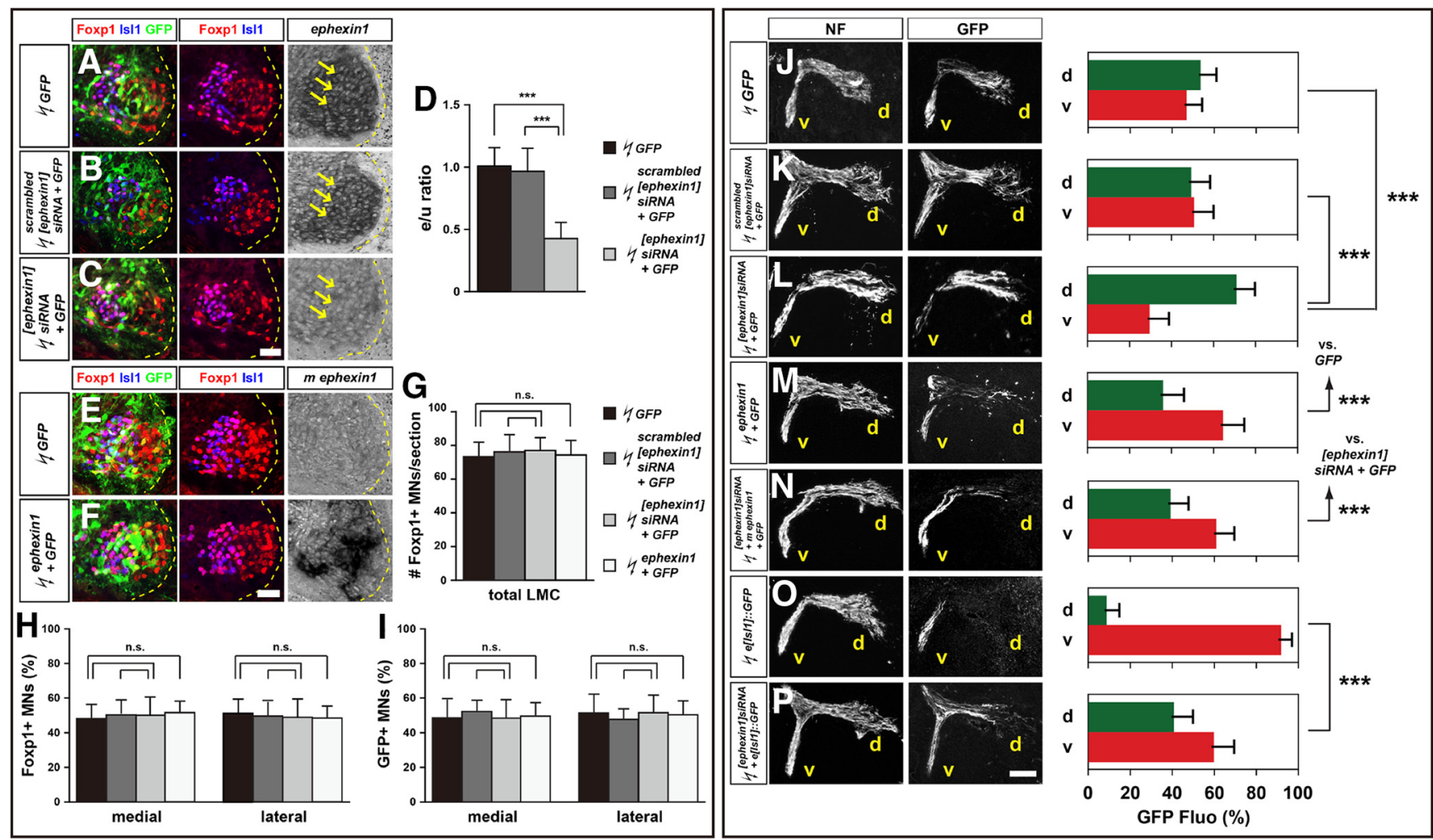

Figure 2. Ephexin 1 function is required for the selection of limb axon trajectory. All images are from chick HH stage 28/29 lumbar levels. A-C, Detection of Foxp1, Isl1, GFP, and ephexin 1 in LMC neurons of chick embryos electroporated with GFP $(\boldsymbol{A})$, scrambled [ephexin1] siRNA, and GFP (B), or with [ephexin1]siRNA and GFP( $\boldsymbol{C}$. D , Quantification of effects of GFP electroporation, of scrambled [ephexin 1]siRNA and GFP electroporation, or of [ephexin 1]siRNA and GFP electroporation on ephexin1 mRNA levels. The ratio of immunoreactivity signal levels in LMC neurons of the electroporated to the unelectroporated contralateral side (e/u ratio) was obtained in $\geq 20$ sections of six embryos. E, F, Detection of Is 1 , Foxp1, and GFP protein and mouse ephexin $1 \mathrm{mRNA}$ in the LMC of chick HH stage 28/29 electroporated with GFP(E) or ephexin 1 and GFP $(\boldsymbol{F})$ expression plasmids. $\boldsymbol{G}$, Number of LMC motor neurons expressed as the average number of total (Foxp $\left.{ }^{+}\right)$LMC neurons per section (\# Foxp $1^{+}$MNs/section). Number of embryos: $n=5$ for all groups. $\boldsymbol{H}, \mathbf{I}$, Number of total or electroporated medial (Foxp $1^{+}|\mathrm{sl}| 1^{+}$) and lateral (Foxp $1^{+} \mid \mathrm{ISI} 1^{-}$) $\mathrm{LMC}$ motor neurons in lumbar spinal cord expressed as the percentage of total motor neurons $\left[\right.$ Foxp $1^{+}$MNs $\left.(\%) ; \boldsymbol{H}\right]$ or electroporated motor neurons $\left[G F P^{+}\right.$MNs $(\%)$; $]$. Number of embryos: $n=5$ for all groups. $J-P$, Neurofilament and GFP detection in the limb nerve branches in the crural plexus of chick embryos electroporated with the following expression plasmids and siRNAs: GFP (J); scrambled [ephexin 1]siRNA and GFP $(\boldsymbol{K})$; [ephexin1]siRNA and GFP $(\boldsymbol{L})$; ephexin1 and GFP $(\boldsymbol{M})$; [ephexin1]siRNA, mouse ephexin1, and GFP $(\boldsymbol{N})$; medial LMC axonal marker e[Is/1]]:GGP (0); or [ephexin1]siRNA and e[Is/1]]:GFP (P). Quantification of GFP signals in all electroporation experiments expressed as, respectively, percentage in dorsal and ventral limb nerves [GFP Fluo (\%)]. Number of embryos: $n=5$ for all groups. $d$, Dorsal; v, ventral; error bars, SD; n.s., not significant; ${ }^{* *} p<0.001$; statistical significance computed using Mann-Whitney U test; all values are mean $\pm S D$. Scale bar: (in $\left.\boldsymbol{F}\right) \boldsymbol{A}-\boldsymbol{C}, \boldsymbol{E}, \boldsymbol{F}, 45 \mu \mathrm{m}$; (in P) $J-0,150 \mu \mathrm{m}$.

of limb axon trajectory by medial LMC neurons (Fig. 3A-G; $p=$ $\left.2.77^{\star} 10^{-4}\right)$. On the other hand, the proportion of lateral LMCs labeled by ventral limb HRP injections was also significantly higher in ephexin1-knockdown embryos when compared with controls (Fig. $3 H-M ; p=0.0072$ ). These observations thus confirm that ephexin1 knockdown results in a loss of fidelity of limb trajectory choice by LMC axons, and that medial LMC axons, compared with lateral LMC axons, rely more on ephexin1 expression.

\section{Asymmetric ephexin1-knockdown sensitivity of the LMC trajectory choice}

To ascertain whether ephexin1 function is required for LMC axon trajectory selection, we examined the LMC axon trajectory in ephexin1 mutant mice (Fig. 4A-H). The specification and survival of LMC neurons were normal in ephexin $1^{-1-}$ mice compared with wild-type littermates (Fig. 4I; $p=0.5125$; Fig. 4J; $p=$ 0.8397). To trace the trajectory of LMC axons, we labeled LMC neurons by HRP retrograde tracer injection into the dorsal or ventral shank muscles of E12.5 ephexin $1^{-/-}$and wild-type littermate embryos and quantified the proportions of tracer-filled LMC neurons that expressed Isl1 and Lim1 (Kania et al., 2000; Kao et al., 2009). The proportion of medial LMC neurons labeled by dorsal limb HRP injection was significantly higher in ephexin $1^{-1-}$ embryos when compared with control embryos (Fig. $4 K-O ; p=5.18^{\star} 10^{-5}$ ). The proportion of lateral LMC neurons labeled by ventral limb HRP injection was also significantly higher, but to a lesser extent, in ephexin $1^{-/-}$embryos when compared with control embryos (Fig. $4 Q-U ; p=7.79^{*} 10^{-3}$ ). These observations demonstrate that ephexin 1 function is required for the selection of appropriate LMC axon trajectories and that the dependence on ephexin 1 function is different between medial and lateral LMC neurons (Fig. $4 P, V$ ).

\section{Ephexin1 is required for ephrin-mediated, but not} netrin-mediated, motor axon responses

Researchers have suggested that ephexin 1 acts as a downstream effector of Eph signaling in several contexts (Shamah et al., 2001; Knöll and Drescher, 2004; Egea et al., 2005; Sahin et al., 2005; Frank et al., 2009; Defourny et al., 2013). Also, ephrin:Eph signaling is sufficient to redirect LMC axons (Kania and Jessell, 2003; Luria et al., 2008). To investigate the dependence of Eph signaling on ephexin 1 function, we tested the response of LMC axons to stripes of ephrin-A or ephrin-B proteins in the context of ephexin1 loss of function (Kao and Kania, 2011). HH stage 25/26 LMC explants were dissected and placed onto carpets of two alternating stripes: those containing a mixture of ephrin-Fc and a 
Table 2. Quantifications of figures

\begin{tabular}{|c|c|c|}
\hline Figure & Construct or element in figure & Quantification \\
\hline \multirow[t]{3}{*}{$2 F$} & GFP & $1.00 \pm 0.14$ \\
\hline & [ephexin1] siRNA + GFP & $0.42 \pm 0.12$ \\
\hline & scrambled [ephexin1] siRNA + GFP & $0.97 \pm 0.19$ \\
\hline \multirow[t]{4}{*}{$2 G$} & GFP & $73.3 \pm 8.8$ \\
\hline & [ephexin1] siRNA + GFP & $76.2 \pm 1.00$ \\
\hline & scrambled [ephexin1] siRNA + GFP & $76.9 \pm 6.5$ \\
\hline & ephexin $1+$ GFP & $74.3 \pm 7.9$ \\
\hline \multirow[t]{8}{*}{$2 \mathrm{H}$} & GFP medial & $48.2 \pm 7.4 \%$ \\
\hline & GFP lateral & $51.8 \pm 7.4 \%$ \\
\hline & [ephexin1] siRNA + GFP medial & $50.3 \pm 8.0 \%$ \\
\hline & [ephexin1] siRNA + GFP lateral & $49.7 \pm 8.0 \%$ \\
\hline & scrambled [ephexin1] siRNA + GFP medial & $50.2 \pm 9.6 \%$ \\
\hline & scrambled [ephexin1] siRNA + GFP lateral & $49.8 \pm 9.6 \%$ \\
\hline & ephexin1 + GFP medial & $51.6 \pm 6.6 \%$ \\
\hline & ephexin1 + GFP lateral & $48.4 \pm 6.6 \%$ \\
\hline \multirow[t]{8}{*}{21} & GFP medial & $48.7 \pm 10.9 \%$ \\
\hline & GFP lateral & $51.3 \pm 10.9 \%$ \\
\hline & [ephexin1] siRNA + GFP medial & $52.3 \pm 6.1 \%$ \\
\hline & [ephexin1] siRNA + GFPlateral & $47.7 \pm 6.1 \%$ \\
\hline & scrambled [ephexin1] siRNA + GFP medial & $48.5 \pm 10.2 \%$ \\
\hline & scrambled [ephexin1] siRNA + GFP lateral & $51.5 \pm 10.2 \%$ \\
\hline & ephexin1 + GFP medial & $49.7 \pm 7.8 \%$ \\
\hline & ephexin1 + GFPlateral & $50.3 \pm 7.8 \%$ \\
\hline \multirow[t]{2}{*}{2} & Dorsal & $53.3 \pm 7.3 \%$ \\
\hline & Ventral & $46.7 \pm 7.3 \%$ \\
\hline \multirow[t]{2}{*}{$2 K$} & Dorsal & $49.3 \pm 9.3 \%$ \\
\hline & Ventral & $50.7 \pm 9.3 \%$ \\
\hline \multirow[t]{2}{*}{$2 L$} & Dorsal & $70.6 \pm 9.1 \%$ \\
\hline & Ventral & $9.4 \pm 9.1 \%$ \\
\hline \multirow[t]{2}{*}{$2 M$} & Dorsal & $35.8 \pm 10.2 \%$ \\
\hline & Ventral & $64.2 \pm 10.2 \%$ \\
\hline \multirow[t]{2}{*}{$2 N$} & Dorsal & $39.1 \pm 8.5 \%$ \\
\hline & Ventral & $60.9 \pm 8.5 \%$ \\
\hline \multirow[t]{2}{*}{20} & Dorsal & $8.6 \pm 5.7 \%$ \\
\hline & Ventral & $91.4 \pm 5.7 \%$ \\
\hline \multirow[t]{2}{*}{$2 P$} & Dorsal & $40.5 \pm 9.6 \%$ \\
\hline & Ventral & $59.5 \pm 9.6 \%$ \\
\hline \multirow[t]{2}{*}{$3 G$} & Control & $4.2 \pm 2.6 \%$ \\
\hline & $\mathrm{KD}$ & $7.6 \pm 5.1 \%$ \\
\hline \multirow[t]{2}{*}{$3 N$} & Control & $3.7 \pm 2.7 \%$ \\
\hline & $\mathrm{KD}$ & $5.1 \pm 4.4 \%$ \\
\hline \multirow[t]{2}{*}{41} & $+1+$ & $107.0 \pm 12.4$ \\
\hline & $-1-$ & $108.8 \pm 18.5$ \\
\hline \multirow[t]{4}{*}{ 4J } & $+/+$ medial & $50.5 \pm 4.7 \%$ \\
\hline & $-/-$ medial & $51.5 \pm 5.5 \%$ \\
\hline & $+/+$ lateral & $49.5 \pm 4.7 \%$ \\
\hline & $-/-$ lateral & $49.0 \pm 5.5 \%$ \\
\hline \multirow[t]{2}{*}{40} & $+1+$ & $3.1 \pm 1.8 \%$ \\
\hline & $-1-$ & $31.2 \pm 6.3 \%$ \\
\hline $4 U$ & $+/+$ & $4.6 \pm 2.1 \%$ \\
\hline & $-1-$ & $15.7 \pm 5.5 \%$ \\
\hline $5 A$ & eB2 & $27.7 \pm 8.8 \%$ \\
\hline & $\mathrm{Fc}$ & $72.3 \pm 8.8 \%$ \\
\hline $5 B$ & eB2 & $47.9 \pm 7.7 \%$ \\
\hline & $\mathrm{Fc}$ & $52.1 \pm 7.7 \%$ \\
\hline $5 C$ & $\mathrm{~N}$ & $29.4 \pm 10.4 \%$ \\
\hline & $\mathrm{Fc}$ & $70.6 \pm 10.4 \%$ \\
\hline $5 D$ & $\mathrm{~N}$ & $33.8 \pm 10.1 \%$ \\
\hline & $\mathrm{Fc}$ & $66.2 \pm 10.1 \%$ \\
\hline $5 E$ & eA5 & $26.5 \pm 6.9 \%$ \\
\hline & $\mathrm{Fc}$ & $73.5 \pm 6.9 \%$ \\
\hline $5 F$ & eA5 & $39.2 \pm 9.2 \%$ \\
\hline & $\mathrm{Fc}$ & $60.8 \pm 9.2 \%$ \\
\hline
\end{tabular}

Table 2. Continued

\begin{tabular}{|c|c|c|}
\hline Figure & Construct or element in figure & Quantification \\
\hline \multirow[t]{2}{*}{$5 G$} & $\mathrm{~N}$ & $70.4 \pm 9.7 \%$ \\
\hline & $\mathrm{Fc}$ & $29.6 \pm 9.7 \%$ \\
\hline \multirow[t]{2}{*}{$5 H$} & $\mathrm{~N}$ & $63.3 \pm 10.3 \%$ \\
\hline & $\mathrm{Fc}$ & $36.7 \pm 10.3 \%$ \\
\hline \multirow[t]{2}{*}{$6 A$} & Dorsal & $87.2 \pm 6.6 \%$ \\
\hline & Ventral & $12.8 \pm 6.6 \%$ \\
\hline \multirow[t]{2}{*}{$6 B$} & Dorsal & $69.9 \pm 9.0 \%$ \\
\hline & Ventral & $30.1 \pm 9.0 \%$ \\
\hline \multirow[t]{2}{*}{$6 C$} & Dorsal & $32.2 \pm 8.0 \%$ \\
\hline & Ventral & $67.8 \pm 8.0 \%$ \\
\hline \multirow[t]{2}{*}{$6 D$} & Dorsal & $55.7 \pm 10.6 \%$ \\
\hline & Ventral & $44.3 \pm 10.6 \%$ \\
\hline \multirow[t]{2}{*}{$6 G$} & EphB2::GFP & $21.3 \pm 5.8 \%$ \\
\hline & [ephexin1] siRNA + EphB2::GFP & $5.5 \pm 3.3 \%$ \\
\hline \multirow[t]{2}{*}{$7 A$} & $\mathrm{eB} 2$ & $29.2 \pm 6.3 \%$ \\
\hline & $\mathrm{Fc}$ & $70.9 \pm 6.3 \%$ \\
\hline \multirow[t]{2}{*}{$7 B$} & eB2 & $15.5 \pm 5.8 \%$ \\
\hline & $\mathrm{Fc}$ & $84.5 \pm 5.8 \%$ \\
\hline \multirow[t]{2}{*}{$7 C$} & eB2 & $43.4 \pm 8.2 \%$ \\
\hline & $\mathrm{Fc}$ & $56.6 \pm 8.2 \%$ \\
\hline \multirow[t]{2}{*}{70} & eB2 & $15.1 \pm 5.3 \%$ \\
\hline & $\mathrm{Fc}$ & $84.9 \pm 5.3 \%$ \\
\hline \multirow[t]{2}{*}{$7 E$} & eB2 & $44.7 \pm 6.3 \%$ \\
\hline & $\mathrm{Fc}$ & $55.3 \pm 6.3 \%$ \\
\hline \multirow[t]{2}{*}{$7 F$} & eB2 & $31.3 \pm 6.6 \%$ \\
\hline & $\mathrm{Fc}$ & $68.7 \pm 6.6 \%$ \\
\hline \multirow[t]{2}{*}{$7 G$} & eB2 & $46.1 \pm 4.5 \%$ \\
\hline & $\mathrm{Fc}$ & $53.9 \pm 4.5 \%$ \\
\hline \multirow[t]{2}{*}{$7 H$} & eB2 & $44.2 \pm 7.8 \%$ \\
\hline & $\mathrm{Fc}$ & $55.8 \pm 7.8 \%$ \\
\hline \multirow[t]{2}{*}{$7 K$} & GFP & $77.2 \pm 8.5$ \\
\hline & ephexin $1^{Y 87 F}+$ GFP & $79.7 \pm 7.6$ \\
\hline \multirow[t]{4}{*}{$7 L$} & GFP medial & $51.1 \pm 6.2 \%$ \\
\hline & GFP lateral & $48.9 \pm 6.2 \%$ \\
\hline & ephexin $1^{Y 87 F}+$ GFP medial & $52.3 \pm 5.7 \%$ \\
\hline & ephexin $^{\text {Y87F }}+$ GFP lateral & $47.7 \pm 5.7 \%$ \\
\hline \multirow[t]{4}{*}{$7 M$} & GFP medial & $48.8 \pm 5.2 \%$ \\
\hline & GFP lateral & $51.2 \pm 5.2 \%$ \\
\hline & ephexin $7^{\text {Y87F }}+$ GFP medial & $51.9 \pm 7.8 \%$ \\
\hline & ephexin $7^{\text {Y87F }}+$ GFP lateral & $48.1 \pm 7.8 \%$ \\
\hline \multirow[t]{2}{*}{$7 N$} & Dorsal & $52.1 \pm 8.8 \%$ \\
\hline & Ventral & $47.9 \pm 8.8 \%$ \\
\hline \multirow[t]{2}{*}{70} & Dorsal & $31.1 \pm 9.1 \%$ \\
\hline & Ventral & $68.9 \pm 9.1 \%$ \\
\hline \multirow[t]{2}{*}{$7 P$} & Dorsal & $58.8 \pm 7.4 \%$ \\
\hline & Ventral & $41.2 \pm 7.4 \%$ \\
\hline \multirow[t]{2}{*}{70} & Dorsal & $34.3 \pm 10.2 \%$ \\
\hline & Ventral & $65.7 \pm 10.2 \%$ \\
\hline $7 R$ & Dorsal & $62.4 \pm 7.9 \%$ \\
\hline & Ventral & $37.6 \pm 7.9 \%$ \\
\hline
\end{tabular}

Cy3 secondary antibody and those containing Fc protein only. Medial LMC axons were identified by e[Isl1]::GFP electroporation, whereas lateral LMC axons were identified by their EphA4 expression. Stripe preference was scored as the proportion of GFP or EphA4 signal found over the different stripes after overnight explant culture (Kao and Kania, 2011; Kao et al., 2015).

Medial LMC neurons coelectroporated with [ephexin1]siRNA and $e[$ Isl1]::GFP exhibited significantly attenuated repulsion from ephrin-B2 stripes compared with controls expressing $e[$ Isl1]::GFP only, suggesting that ephexin1 is required for EphBmediated medial LMC axon repulsion from ephrin-B2 (Fig. $\left.5 A, B ; p=7.75^{\star} 10^{-4}\right)$. Due to recent findings showing netrin-1 signaling as another major pathway to modulate LMC axon tra- 


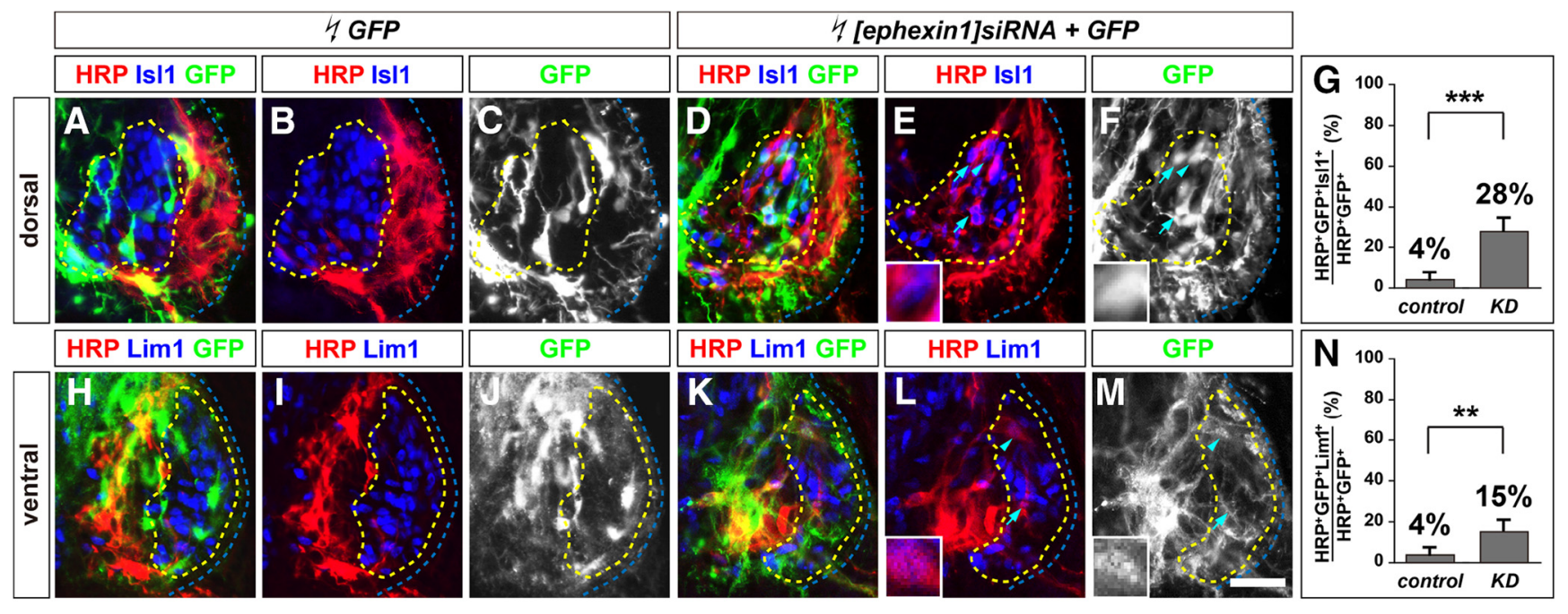

Figure 3. Ephexin 1 function is required for the fidelity of $L M C$ motor axon limb trajectories. Retrograde labeling of $L M C$ neurons by HRP injections into the dorsal or ventral limb muscles of chick HH stage 28/29 embryos. $\boldsymbol{A}-\boldsymbol{F}$, Detection of HRP, Lim1, and GFP in the LMC regions of GFP $(\boldsymbol{A}-\boldsymbol{C})$ or of [ephexin 1] siRNA and GFP $(\boldsymbol{D}-\boldsymbol{F})$ electroporated embryos injected with HRP into dorsal hindlimb shank muscles. Examples of $\mathrm{HRP}^{+} \mathrm{GFP}^{+}$neurons are indicated by arrows and arrowheads $(\boldsymbol{E}, \boldsymbol{F}) \cdot \boldsymbol{E}, \boldsymbol{F}$, Insets, Examples indicated by arrowheads are shown at higher magnification. $\boldsymbol{G}$, Proportions of electroporated medial LMC motor neurons labeled with HRP in dorsally filled embryos. Number of embryos: $n=5$ for all groups. $\boldsymbol{H}-\boldsymbol{M}$, Detection of HRP, Lim1, and GFP in the LMC regions of GFP $(\boldsymbol{H}-\boldsymbol{J})$ or of [ephexin1]siRNA and GFP $(\boldsymbol{K}-\boldsymbol{M})$ electroporated embryos injected with HRP into ventral hindlimb shank muscles. Examples of $\mathrm{HRP}^{+} \mathrm{GFP}^{+}$neurons are indicated by arrows and arrowheads $(L, M) . L, M$, Insets, Examples indicated by arrowheads are shown at higher magnification. $N$, Proportions of electroporated lateral $L M C$ motor neurons labeled with HRP in ventrally filled embryos. Number of embryos: $n=5$ for all groups. control, GFP electroporated groups; KD, [ephexin1] siRNA and GFP electroporated groups; error bars, SD; ${ }^{* *} p<0.001 ;{ }^{* *} p<0.01$; statistical significance computed using Fisher's exact test; all values are mean \pm SD. Scale bars: (in $\boldsymbol{M}) \boldsymbol{A}-\boldsymbol{F}, \boldsymbol{H}-\boldsymbol{M}, 45 \mu \mathrm{m} ; \boldsymbol{E}, \boldsymbol{F}, \boldsymbol{L}, \boldsymbol{M}$, insets, $8 \mu \mathrm{m}$.

jectory into the limb (Poliak et al., 2015), we also tested the response of medial LMC axons to stripes of netrin-1 proteins in the context of ephexin 1 loss of function. In contrast to those challenged with ephrin-B2 stripes, medial LMC neurons coelectroporated with [ephexin1] siRNA and e[Isl1]::GFP exhibited normal avoidance of netrin-1 stripes compared with controls expressing $e[$ Isl1]::GFP only (Fig. 5C,D; $p=0.2872$ ), suggesting that ephexin1 does not play an important role in netrin-1-mediated medial LMC axon guidance in vitro.

On the other hand, lateral LMC neurons coelectroporated with [ephexin1] siRNA and GFP exhibited significantly attenuated repulsion from ephrin-A5 stripes compared with controls expressing GFP only, suggesting that ephexin1 is required for EphA-mediated lateral LMC axon repulsion from ephrin-A5 (Fig. $5 E, F ; p=0.0371$ ). Next, we tested the response of lateral LMC axons to stripes of netrin-1 proteins and observed that lateral LMC neurons coelectroporated with [ephexin1] siRNA and GFP exhibited normal neurite attractive preference on netrin-1 stripes compared with controls expressing GFP only (Fig. 5G,H; $p=0.1126$ ), suggesting that ephexin 1 does not play an important role in netrin-1-mediated lateral LMC axon guidance in vitro. In sum, these results demonstrate that ephexin1 is essential for ephrin-A-mediated and ephrin-B-mediated LMC axon responses, but not netrin-1- mediated LMC axon responses.

\section{Ephexin1 is required for Eph signaling-directed LMC motor axon guidance}

To ascertain the role of ephexin1 in Eph signal transduction in vivo, we tested whether ephexin1 loss can attenuate the axon redirection effects of Eph overexpression (Kania and Jessell, 2003; Luria et al., 2008). To do this, we coelectroporated [ephexin1]siRNA with the Eph receptor-GFP fusion protein expression plasmids EphA4::GFP or EphB2::GFP and compared them with control EphA4::GFP and EphB2::GFP plasmid electroporations. EphA4::GFP electroporation in control embryos, as previously demonstrated (Eberhart et al., 2002; Kania and Jessell, 2003), induced a robust redirection of LMC axons into the dorsal limb nerves (Fig. 6A). In embryos coelectroporated with [ephexin1] siRNA and EphA4::GFP, proportions of axonal GFP levels in ventral branches were significantly increased compared with EphA4::GFP-electroporated controls (Fig. 6A,B; $p=0.0250)$, indicating that ephexin1 knockdown attenuates EphA4-induced LMC motor axon redirection. On the other hand, in embryos electroporated with EphB2::GFP alone, a higher proportion of $\mathrm{GFP}^{+}$axons was observed in ventral LMC axons, suggesting that EphB2 overexpression is sufficient to redirect LMC axons into the ventral limb (Fig. 6C; Kao et al., 2009). In embryos coelectroporated with [ephexin1] siRNA and EphB2::GFP, a significantly higher proportion of GFP levels was observed in dorsal nerve branches compared with EphB2::GFP alone, thus indicating that ephexin1 knockdown attenuates EphB2-induced LMC motor axon redirection (Fig. $6 C, D ; p=8.98^{\star} 10^{-4}$ ).

To confirm whether ephexin 1 function is required for EphBmediated lateral LMC axon redirection, we labeled LMC neurons by HRP retrograde tracer injection into the ventral shank muscles of $\mathrm{HH}$ stage 28/29 embryos electroporated with [ephexin1] siRNA and EphB2::GFP expression plasmids or with EphB2::GFP alone and determined the LMC divisional identity of labeled neurons (Fig. 6E,F). The proportion of electroporated lateral LMC neurons labeled by ventral limb HRP injections was significantly lower in ephexin1 knockdown embryos when compared with EphB2::GFP controls, indicating that ephexin 1 is required for the redirection of lateral LMC axon trajectory imposed by EphB overexpression (Fig. 6G-I; $p=0.0055$ ). Together, these observations argue that, in vivo, ephexin 1 loss attenuates LMC axon redirection induced by Eph receptor gain of function, suggesting that ephexin1 participates in Eph signaling in vivo.

\section{Ephexin1 is downstream of Src in Eph signal transduction during LMC pathfinding}

Our previous work demonstrated that two Eph signaling intermediaries, Src and $\alpha 2$-chimaerin, are involved in Eph-mediated LMC pathfinding (Kao et al., 2009, 2015), where Src, like 

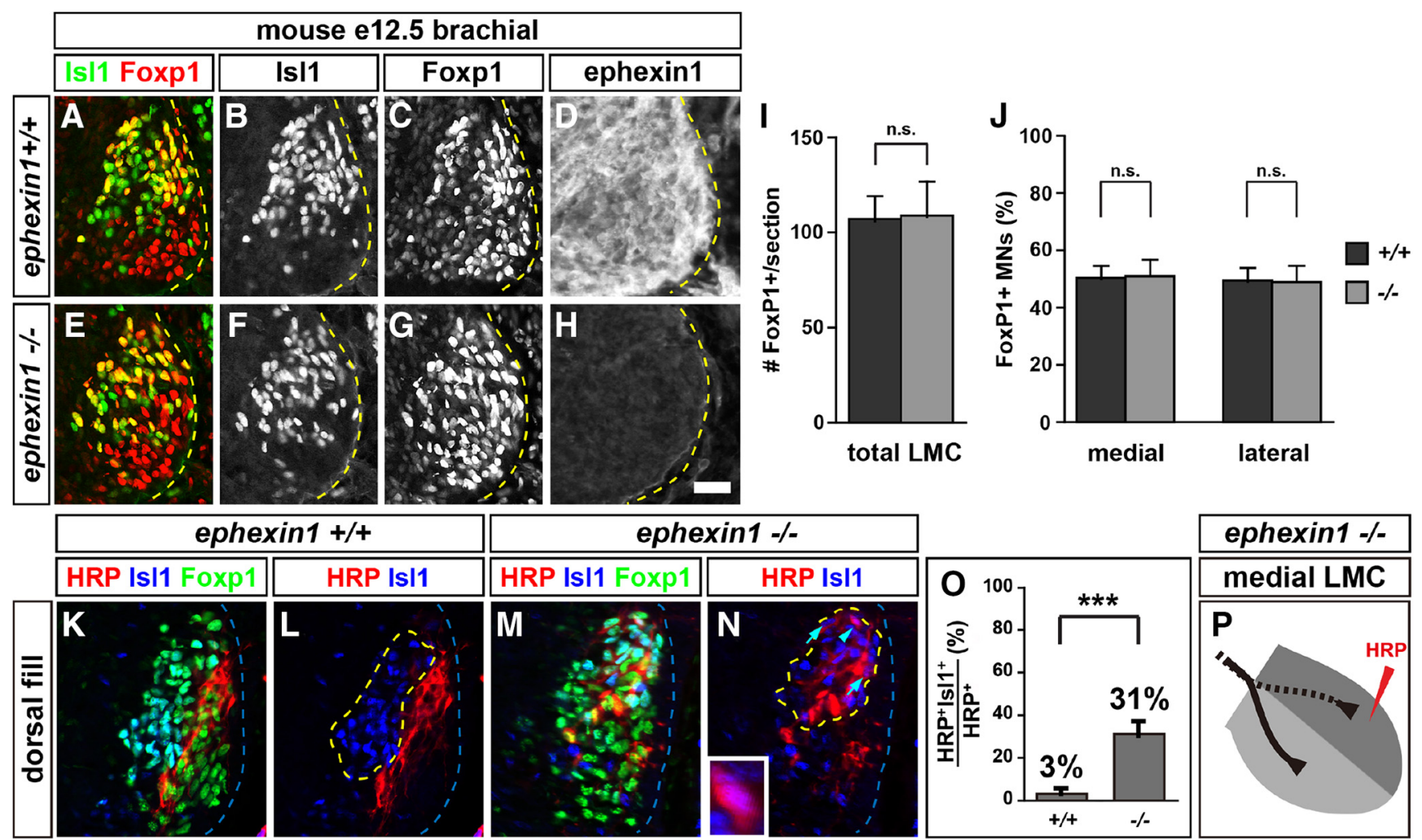

HRP IsI1
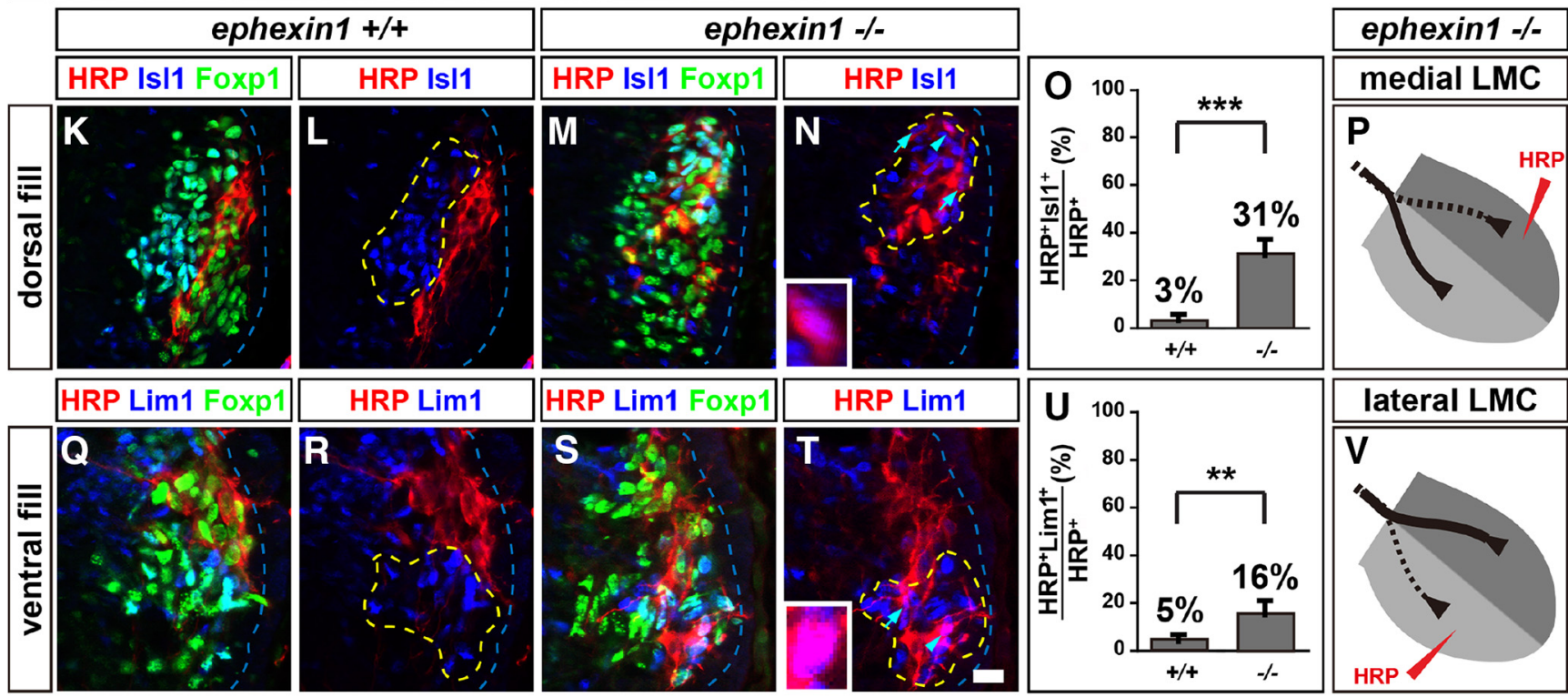

Figure 4. Ephexin 1 is required for the fidelity of $L M C$ motor axon trajectory selection. Retrograde labeling of $L M C$ neurons by HRP injections into the dorsal or ventral limb muscles of mouse E12.5 embryos. $\boldsymbol{A}-\boldsymbol{H}$, Detection of IsI1 (green), Foxp1 (red), and ephexin1 protein in the LMC region at the brachial level of mouse e12.5 ephexin $1^{+/+}(\boldsymbol{A}-\boldsymbol{D})$ or ephexin $1^{-/-}(\boldsymbol{E}-\boldsymbol{H})$ embryos. $\boldsymbol{I}$, Number of LMC motor neurons expressed as the average number of total (Foxp $1^{+}$) LMC neurons per section ( \#FoxP1 ${ }^{+} /$section). Number of embryos: $n=6$ for all groups.J, Number of total medial (FoxP1 ${ }^{+}$

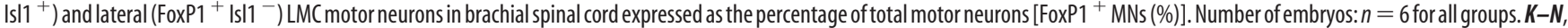
Detection of HRP (red), Isl1 (blue), and Foxp1 (green), which marks all LMC neurons, in the LMC regions of ephexin $1^{+/+}(\boldsymbol{K}, \boldsymbol{L})$ and ephexin $1^{-/-}(\boldsymbol{M}, \boldsymbol{N})$ embryos injected with HRP into dorsal forelimb muscles. Examples of medial LMC motor neurons labeled with HRP are indicated by arrows and arrowheads. Examples indicated by arrowheads are shown at a higher magnification ( $\boldsymbol{N}$, inset). $\mathbf{0}$, Quantification of retrogradely labeled medial LMC axon projections. The graph depicts the mean percentage \pm SD of HRP ${ }^{+}$motor neurons that express the medial LMC marker IsI1 following a dorsal limb injection. Numbers of embryos: $n=4$ for all groups. $P$, Summary scheme of medial LMC projections in ephexin $1^{-/-}$mice, depicting a significant misrouting of medial LMC axons into the dorsal limb. Q- $\boldsymbol{T}$, Detection of HRP (red), Lim1 (blue), and Foxp1 (green) in the LMC regions of ephexin $1^{+/+}(\mathbf{Q}, \boldsymbol{R})$ and ephexin $1^{-/-}(\boldsymbol{S}, \boldsymbol{T})$ embryos injected with HRP into ventral forelimb muscles. Examples of lateral LMC motor neurons labeled with HRP are indicated by arrows and arrowheads. Examples indicated by arrowheads are shown at a higher magnification ( $\boldsymbol{T}$, inset). $\boldsymbol{U}$, Quantification of retrogradely labeled lateral LMC axon projections. The graph depicts the mean percentage \pm SD of HRP ${ }^{+}$motor neurons that express the lateral LMC marker Lim1 following a ventral limb injection. Number of embryos: $n=4$ for all groups. $\boldsymbol{V}$, Summary scheme of lateral LMC projections in ephexin $1^{-1-}$ mice, depicting a significant misrouting of lateral LMC axons into the ventral limb. Error bars, SD; n.s., not significant; ${ }^{* * *} p<0.001$; ${ }^{* *} p<0.01$; statistical significance computed using Fisher's exact test; all values are mean \pm SD. Scale bars: (in $\left.\boldsymbol{H}\right) \boldsymbol{A}-\boldsymbol{H}$, $20 \mu \mathrm{m}$; (in $\boldsymbol{T}) \boldsymbol{K}-\boldsymbol{N}, \mathbf{Q}-\boldsymbol{T}, 20 \mu \mathrm{m} ; \boldsymbol{N}, \boldsymbol{T}$, insets, $7 \mu \mathrm{m}$.

ephexin1, is required in LMC subdivisions differentially. Previous studies also suggested ephexin1 as a potential target of Src tyrosine phosphorylation (Knöll and Drescher, 2004; Sahin et al., 2005). We thus examined the interaction of Src and ephexin1 in EphB signal transduction during medial LMC motor axon pathfinding, where both Src and ephexin 1 are potentially required. We first investigated whether ephexin1 is required for Srcmediated repulsion of medial LMC axons from ephrin-B2. Medial LMC neurons coexpressing e[Isl1]::GFP and Src expression plasmids showed significantly higher levels of repulsion from ephrin-B2 stripes compared with controls expressing e[Isl1]::
GFP alone, which confirmed that Src is required for EphBmediated medial LMC axon repulsion from ephrin-B2 (Fig. $7 A, B ; p=0.0367$; Kao et al., 2009). We then coelectroporated $e[I s l 1]:: G F P$ with a Src expression plasmid and [ephexin1]siRNA and compared that with e[Isl1]::GFP and Src plasmid coelectroporation. Medial LMC neurons coexpressing e[Isl1]::GFP, Src, and [ephexin1] siRNA exhibited significantly attenuated repulsion from ephrin-B2 stripes compared with $e[I s l 1]:: G F P$ and Src plasmid coelectroporation (Fig. $7 B, C ; p=3.52^{\star} 10^{-4}$ ). These observations suggest that ephexin1 acts downstream of Src in EphB signaling to mediate the repulsion of medial LMC axons from ephrin-B2. 

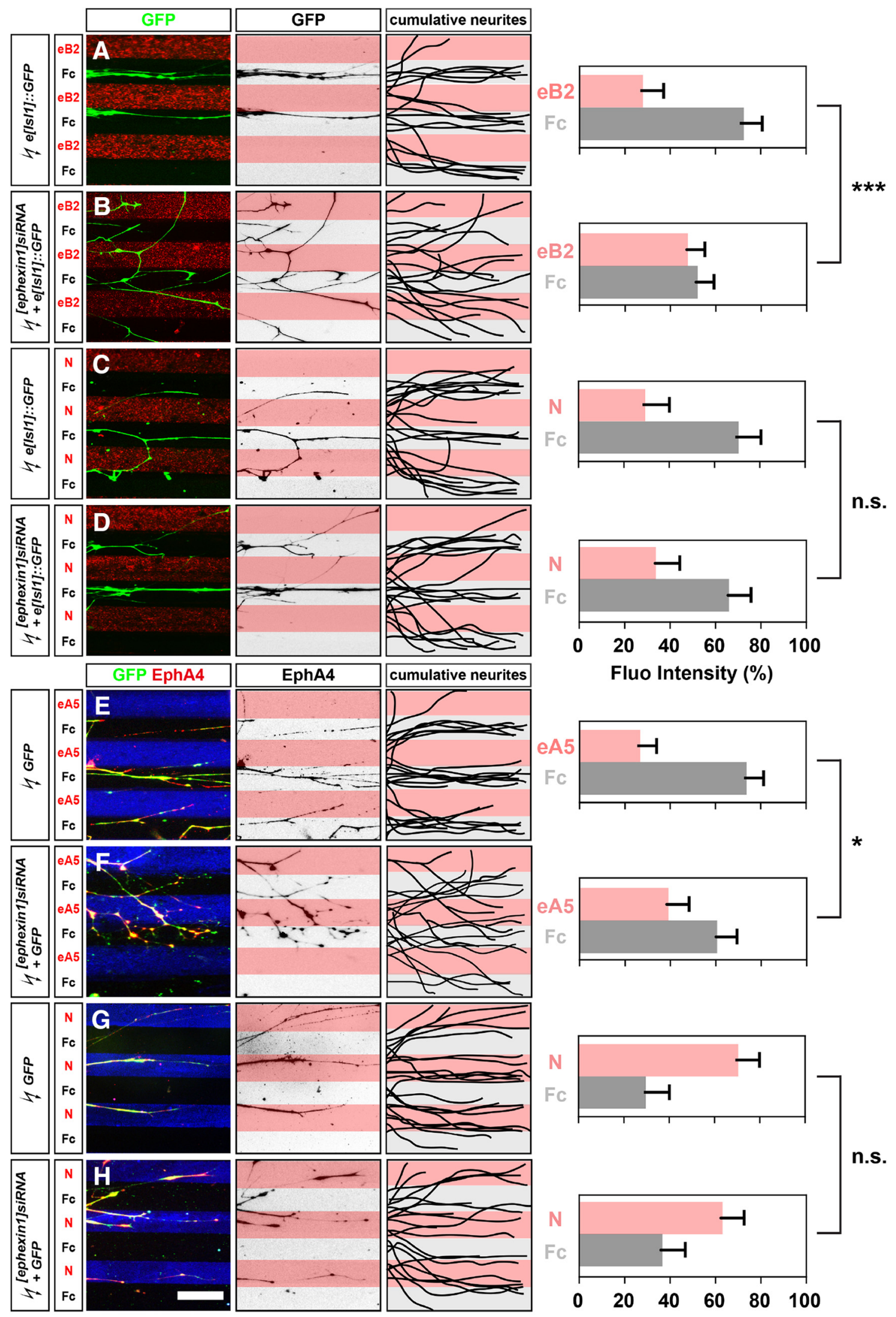

n.s.
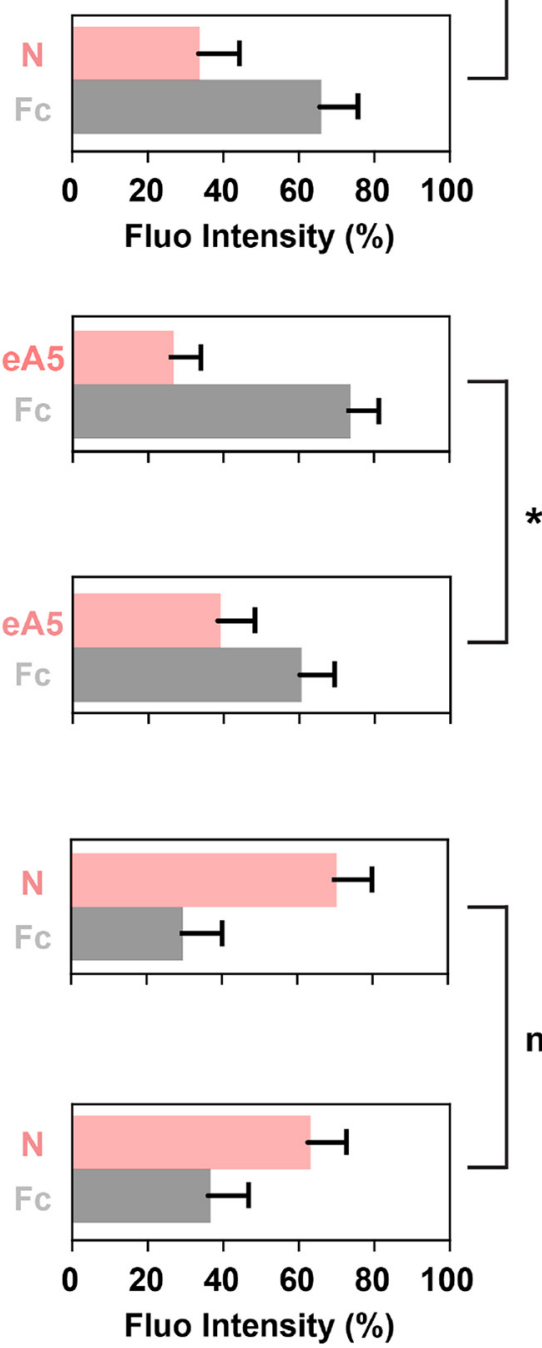

Figure 5. Ephexin1 function is required for ephrin-mediated but not netrin-mediated guidance of cultured LMC neurites. Growth preference on protein stripes exhibited by medial or lateral LMC axons. Each experiment is composed of three panels (left, middle, and right) and one quantification. $\boldsymbol{A}-\boldsymbol{D}$, Left, Detection of medial $\left(G F P{ }^{+}\right) \operatorname{LMC}$ neurites of explants on eB2/Fc $(\boldsymbol{A})$ or N/Fc $(\boldsymbol{C})$ stripes, and of [ephexin1]siRNA coelectroporated explants on eB2/Fc $(\boldsymbol{B})$ or N/Fc $(\boldsymbol{D})$ stripes. Middle, Inverted images where GFP signals are dark pixels overlaid on substrate stripes. Right, Superimposed images of five representative explants from each experimental group, highlighting the distribution of medial LMC neurites. Quantification of medial (GFP ${ }^{+}$) (Figure legend continues.) 

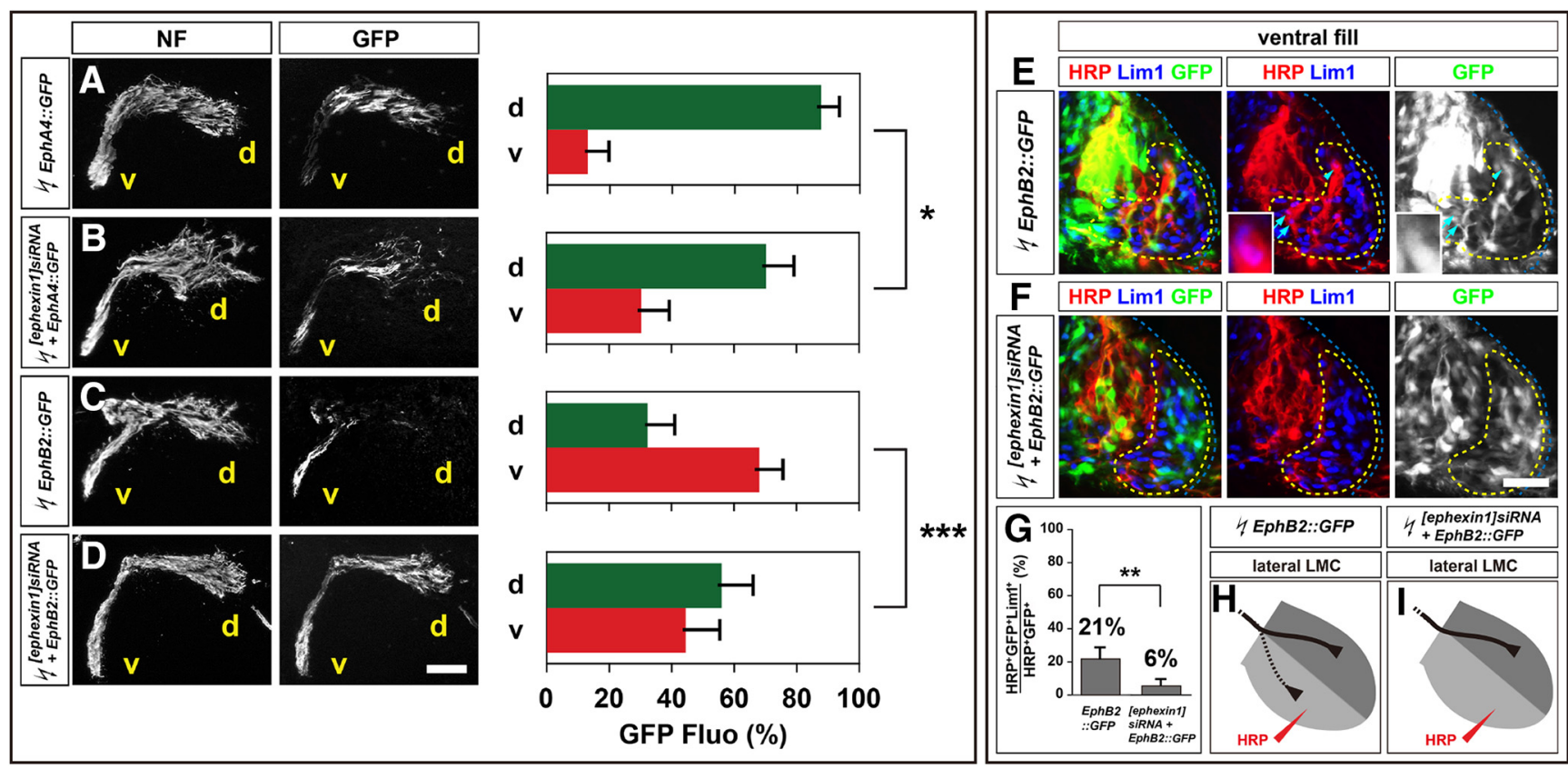

Figure 6. Ephexin1 loss attenuates both EphA4-induced and EphB2-induced LMC motor axon redirection. All images are from chick HH stage 28/29 lumbar levels. $\boldsymbol{A}-\boldsymbol{D}$, Neurofilament and GFP detection in the limb nerve branches in the crural plexus of chick embryos electroporated with the following expression plasmids and siRNAs: EphA4::GFP (A), [ephexin 1]siRNA and EphA4::GFP (B), EphB2::GFP (C), or [ephexin1] siRNA and EphB2::GFP (D). Quantification of GFP signals in all electroporation experiments expressed as, respectively, percentage in dorsal and ventral limb nerves [GFP Fluo (\%)]. Number of embryos: $n=5$ for all groups. $\boldsymbol{E}, \boldsymbol{F}$, Detection of HRP, Lim1, and GFP in the LMC regions of EphB2::GFP-electroporated embryos $(\boldsymbol{E})$ or of embryos electroporated with [ephexin 1] siRNA and EphB2::GFP $(\boldsymbol{F})$ injected with HRP into ventral hindlimb shank muscles. Examples of HRP ${ }^{+}$GFP $^{+}$neurons are indicated by arrows and arrowheads $(\boldsymbol{E})$. Examples indicated by arrowheads are shown at higher magnification ( $\boldsymbol{E}$, insets). $\boldsymbol{G}$, Proportions of electroporated lateral LMC motor neurons labeled with HRP in ventrally filled embryos. Number of embryos: $n=5$ for all groups. $\boldsymbol{H}, \boldsymbol{I}$, Summary scheme of lateral LMC projections in EphB2::GFP-electroporated embryos $(\boldsymbol{H})$ or in embryos electroporated with [ephexin1]siRNA and EphB2::GFP (I), depicting the attenuation of EphB2-induced lateral LMC axon misrouting by ephexin1 knockdown. d, Dorsal; v, ventral; error bars, SD; ${ }^{* * *} p<0.001 ;{ }^{* *} p<0.01$; ${ }^{*} p<0.05$; statistical significance computed using Mann-Whitney $U$ test $(\boldsymbol{A}-\boldsymbol{D})$ or Fisher's exact test $(\boldsymbol{G})$; all values are mean \pm SD. Scale bars: (in $\boldsymbol{D}) \boldsymbol{A}-\boldsymbol{D}, 150 \mu \mathrm{m} ;$ (in $\boldsymbol{F}) \boldsymbol{E}, \boldsymbol{F}, 45 \mu \mathrm{m} ; \boldsymbol{E}$, insets, $8 \mu \mathrm{m}$.

To further dissect Src and ephexin1 interaction in this context, we investigated whether Src inhibition can perturb ephexin1mediated repulsion of medial LMC axons from ephrin-B2. As expected, medial LMC neurons coexpressing e[Isl1]::GFP and ephexin1 expression plasmids showed significantly higher levels of repulsion from ephrin-B2 stripes compared with e[Isl1]::GFP controls (Fig. $7 A, D ; p=0.0220$ ), while medial LMC neurons coexpressing $e[I s l 1]:: G F P$ and Csk showed significantly attenuated repulsion from ephrin-B2 stripes compared with $e[$ [sl1]:: GFP controls (Fig. $7 A, E ; p=6.55^{\star} 10^{-4}$ ), which confirmed that ephexin1 and Src are both required for EphB-mediated medial LMC axon repulsion from ephrin-B2. We then coelectroporated e[Isl1]::GFP with ephexin1 and Csk and compared that with (1) $e[$ Isl1]::GFP and ephexin1 and (2) $e[$ Isl1] ::GFP and Csk coelectroporation. Medial LMC neurons coexpressing e[Isl1]::GFP, ephexin1, and Csk exhibited significantly higher levels of repulsion from ephrin-B2 stripes compared with $e[$ Isll] ::GFP and Csk coelectroporation (Fig. $7 E, F ; p=0.0184$ ), suggesting that

$\leftarrow$

(Figure legend continued.) LMC neurites on first (pink) and second (pale) stripes expressed as a percentage of total GFP signals. Neurites, $n=\geq 85$; explants, $n=\geq 12$. $\boldsymbol{E}-\boldsymbol{H}$, Left, Detection of lateral $\left(\mathrm{GFP}^{+} \mathrm{EphA4}^{+}\right) \mathrm{LMC}$ neurites of explants on eA5/Fc $(\boldsymbol{E})$ or N/Fc $(\boldsymbol{G})$ stripes, and [ephexin1]siRNA coelectroporated explants on eA5/Fc $(\boldsymbol{F})$ or N/Fc $(\boldsymbol{H})$ stripes. Middle, Inverted images where EphA4 signals are dark pixels overlaid on substrate stripes. Right, Superimposed images of five representative explants from each experimental group, highlighting the distribution of lateral LMC neurites. Quantification of lateral (EphA4 ${ }^{+}$) LMC neurites on first (pink) and second (pale) stripes expressed as a percentage of total EphA4 signals. Neurites, $n=\geq 82$; explants, $\geq 11$. eB2, Ephrin-B2-Fc; eA5, ephrin-A5-Fc; N, netrin-1; error bars, SD; ${ }^{* *} p<$ $0.001 ;{ }^{*} p<0.05 ;$ i.s., not significant; statistical significance computed using Mann-Whitney $U$ test; all values are mean \pm SD. Scale bar: (in $\boldsymbol{H}) \boldsymbol{A}-\boldsymbol{H}, 150 \mu \mathrm{m}$. ephexin 1 function in ephrin-B-mediated LMC pathfinding is still at least partially retained following Src family kinase (SFK) inhibition. On the other hand, these neurons exhibited significantly attenuated repulsion from ephrin-B2 stripes compared with $e[I s l 1]:: G F P$ and ephexin1 coelectroporation (Fig. 7D,F; $p=$ 0.0231 ), suggesting that ephexin1 activation could rely on Src activity. To test this idea, we used ephexin $1^{Y 87 F}$ expression plasmid, the inactive mutant form of ephexin 1 that can no longer be phosphorylated by SFKs (Sahin et al., 2005). The specification and survival of LMC neurons were normal in embryos coexpressing ephexin $1^{Y 87 F}$ and GFP compared with GFP controls (Fig. $7 I-L ; p=0.4477$ for total Foxp $1^{+}$neuron numbers/section; $p=$ 0.3980 for the proportions of lateral or medial LMC neurons), and $\mathrm{GFP}^{+}$LMC neurons indicated similar numbers of electroporated cells in both LMC divisions (Fig. 7I,J,M; $p=0.2529$ ). Medial LMC neurons coexpressing ephexin $1^{\text {Y87F }}$ and $e[$ [sl1] ::GFP exhibited significantly attenuated repulsion from ephrin-B2 stripes compared with $e[$ Isll]::GFP-only electroporation (Fig. $\left.7 A, G ; p=1,66^{*} 10^{-5}\right)$. In addition, medial LMC neurons coexpressing $e[I s l 1]:: G F P$, Src, and ephexin $1^{Y 87 F}$ exhibited significantly attenuated repulsion from ephrin-B2 stripes compared with those expressing $e[$ Isl1] ::GFP and Src only (Fig. $7 B, H ; p=$ $\left.4.84^{\star} 10^{-5}\right)$. Together, these results confirm that ephexin1 phosphorylation by Src contributes to EphB-mediated medial LMC axon repulsion from ephrin-B2.

To test this idea in vivo, we knocked down ephexin1 using [ephexin1]siRNA and checked whether the Src-induced LMC motor axon redirection is affected. As shown previously (Kao et al., 2009), in embryos coelectroporated with Src and GFP, a significantly higher proportion of $\mathrm{GFP}^{+}$axons were observed in the 


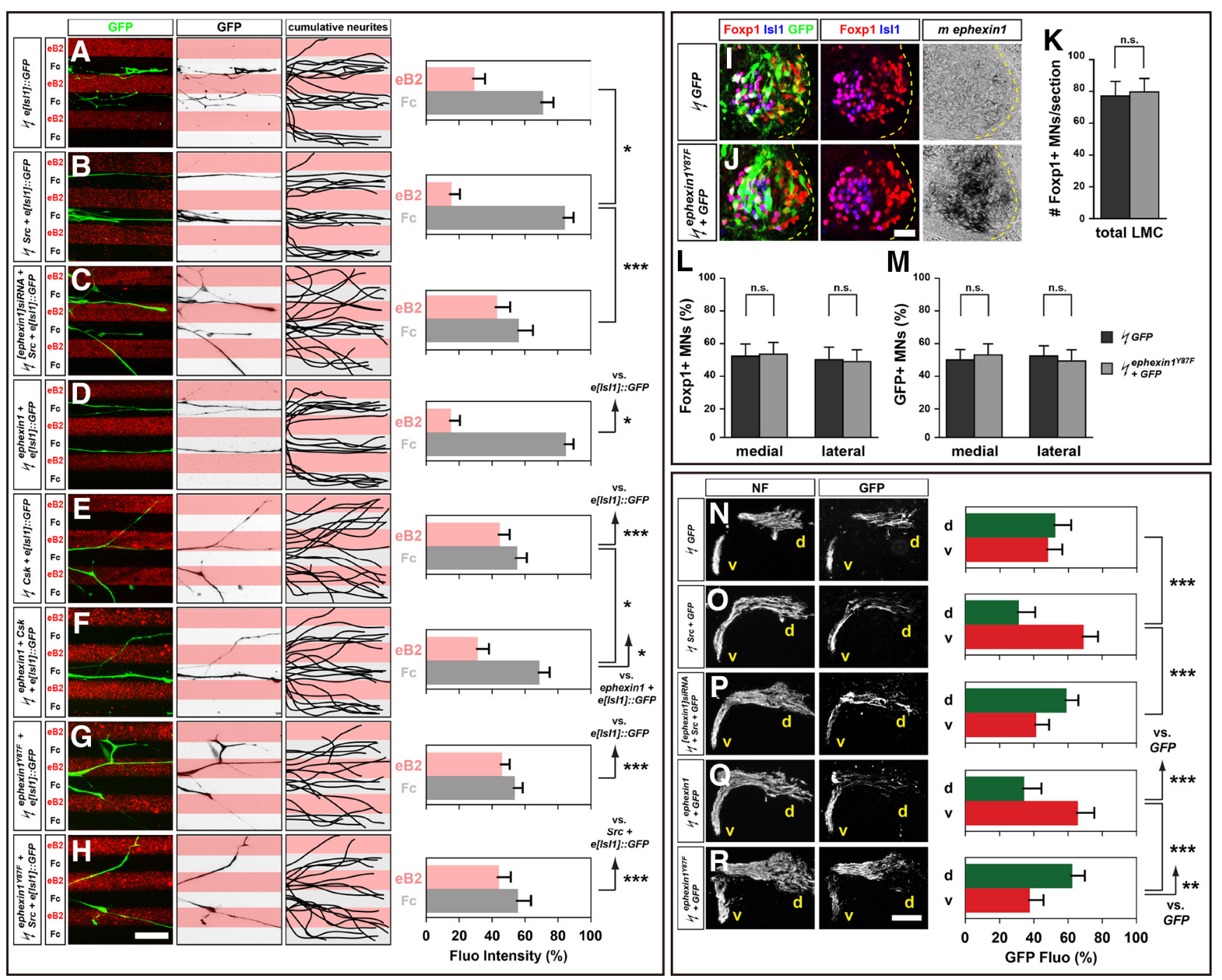

Figure 7. Ephexin 1 functions downstream of Src in Eph-mediated LMC axon guidance. $\boldsymbol{A}-\boldsymbol{H}$, Growth preference on protein stripes exhibited by medial LMC axons. Each experiment is composed of three panels (left, middle, and right) and one quantification. Left, Detection on eB2/Fcstripes of medial (GFP) LMC neurites of explants expressing the following: $[$ [Is/1]]:GFP (A); Src and e[Is/1]]:GFP

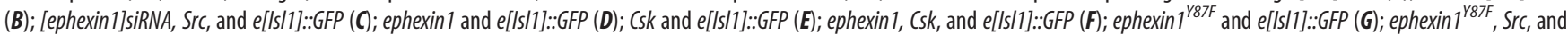
e[Is/1]]:GFP $(\boldsymbol{H})$. Middle, Inverted images where GFP signals are dark pixels overlaid on substrate stripes. Right, Superimposed images of five representative explants from each experimental group, highlighting the distribution of medial LMC neurites. Quantification of medial (GFP ${ }^{+}$) LMC neurites on first (pink) and second (pale) stripes expressed as a percentage of total GFP signals. Neurites, $n \geq 95$; explants, $\mathrm{n} \geq 15$. I, J, Detection of Is $\mid 1$, Foxp1, and GFP protein and mouse ephexin $1 \mathrm{mRNA}$ in the LMC of chick HH stage 28/29 electroporated with GFP (I) or ephexin $1^{\text {Y87F }}$ and GFP (J) expression plasmids. $\boldsymbol{K}$, Number of LMC motor neurons expressed as the average number of total (Foxp $1^{+}$) LMC neurons per section (\# Foxp $1^{+}$MNs/section). Number of embryos: $n=6$ for all groups. $L, M$, Number of total or electroporated medial (Foxp $1^{+}|s| 1^{+}$) and lateral (Foxp $\left.1^{+}|s| 1^{-}\right) L M C$ motor neurons in lumbar spinal cord expressed as the percentage of total motor neurons $\left[\right.$ Foxp $1^{+}$MNs (\%)] (L) or electroporated motor neurons [GFP ${ }^{+}$MNs (\%)] (M). Number of embryos: $n=6$ for all groups. $\boldsymbol{N}-\boldsymbol{R}$, All images are from chick HH stage $28 / 29$ lumbar levels. Neurofilament and GFP detection in the limb nerve branches in the crural plexus of chick embryos electroporated with the following expression plasmids and siRNAs: GFP (N); $\operatorname{Src}$ and GFP (0); [ephexin 1] siRNA, Src, and GFP $(\boldsymbol{P})$; ephexin 1 and GFP $(\mathbf{Q})$; or ephexin $7^{\text {Y87F }}$ and GFP $(\boldsymbol{R})$. Quantification of GFP signals in all electroporation experiments expressed as, respectively, percentage in dorsal and ventral limb nerves [GFP Fluo (\%)]. Number of embryos: $n=6$ for all groups. d, Dorsal; v, ventral; error bars, SD; ${ }^{* * *} p<0.001 ;{ }^{* *} p<0.01 ;{ }^{*} p<0.05 ; n$.. , not significant; statistical significance computed using Mann-Whitney U test; all values are mean \pm SD. Scale bars: (in $\boldsymbol{A}) \boldsymbol{A}-\boldsymbol{H}, 150 \mu \mathrm{m}$; (in $\boldsymbol{J}) \boldsymbol{I}, \boldsymbol{J}, 45 \mu \mathrm{m}$; (in $\boldsymbol{R}) \boldsymbol{N}-\boldsymbol{R}, 150 \mu \mathrm{m}$.

ventral nerve branches when compared with GFP controls (Fig. $\left.7 \mathrm{~N}, O ; p=7.51^{\star} 10^{-4}\right)$, suggesting that $\mathrm{Src}$ overexpression causes a significantly greater proportion of LMC motor axons to enter the ventral limb. In contrast, in embryos coelectroporated with $S r c, G F P$, and [ephexin1] siRNA, a significantly higher proportion of $\mathrm{GFP}^{+}$axons were observed in the dorsal limb nerve compared with embryos coexpressing Src and GFP (Fig. 7O,P; $p=$ $5.42^{\star} 10^{-5}$ ), which indicates that ephexin1 knockdown attenuates Src-induced LMC motor axon redirection. In addition, in embryos coelectroporated with ephexin $1^{\text {Y87F }}$ and GFP expression plasmids, a significantly higher proportion of $\mathrm{GFP}^{+}$axons were observed in the dorsal nerve branches compared with both GFP controls and embryos coelectroporated with ephexin 1 and GFP
(Fig. $7 N, Q, R ; p=0.0076$ vs $G F P, p=6.77^{\star} 10^{-5}$ vs ephexin $1+G F P)$, which confirmed the requirement of ephexin 1 phosphorylation by Src to mediate LMC axon pathfinding. Together, these results suggest that ephexin 1 functions downstream of Src as an essential Eph signaling intermediary to modulate the limb trajectory of LMC motor axons.

\section{Discussion}

Ephexin1 has been proposed to function in signaling pathways essential for growth-cone collapse and axon repulsion. We thus investigated ephexinl's potential roles in vivo and demonstrated that it is essential for the fidelity of motor axon trajectory selection in the limb. Here we discuss the involvement of ephexin 1 at 
multiple LMC axon trajectory decision points, the differential requirement of ephexin1 function by LMC subpopulations, ephexin 1 functional redundancy, and the role of ephexin1 in Eph signal relay.

\section{Ephexin1 involvement in multiple decision points during LMC axon trajectory}

When spinal motor axons reach the base of the limb, they normally stall without obvious outgrowth for $\leq 24 \mathrm{~h}$ before the subsequent axon guidance decision of entering the dorsal versus the ventral limb is made (Wang and Scott, 2000). In LMC neurons, ephexin 1 is proposed to mediate this stalling behavior at the base of the limb: ephexin1 knockdown induces premature entry of motor axons into the limb (Sahin et al., 2005). In our previous work, we also see similar stalling effects in E4 chick LMC neurons (HH stage 22-23) following Src function inhibition by Csk overexpression (Kao et al., 2009; data not shown). Interestingly, both our gain and loss of Src or ephexin1 function in LMC neurons, including Src or ephexin1 mutants and chick embryos, do not show any obvious changes of axon outgrowth at later stages in HH stage 28-29 chick or E11.5-E12.5 mouse embryos. Biochemical evidence suggests that ephexin 1 activity could be regulated by fibroblast growth factor receptors (FGFRs), which are expressed in subpopulations of spinal motor neurons at the corresponding stages of E10.5-E11.5 mouse (Shirasaki et al., 2006; Zhang et al., 2007). The potential functions of FGFs and FGFRs in axon outgrowth and guidance that have been shown in several neuronal types imply that ephexin 1 function may be altered by the combined actions of FGFRs and Ephs, which can form complexes and transactivate each other to transduce signals, in LMC neurons at later stages, when spinal nerves are in contact with ephrins and ready to choose a dorsal versus ventral limb nerve (Bülow et al., 2004; Shirasaki et al., 2006; Zhang et al., 2007; Ponimaskin et al., 2008). Although the detailed mechanisms of temporary motor axon stalling are still unclear, our findings and those of others demonstrate only a transient role for ephexin 1 in the stalling and sorting of motor axons when they arrive the base of the limb, followed by its more essential function in ensuring the proper selection of limb nerve trajectory (Sahin et al., 2005).

\section{The differential requirement of ephexin 1 function by medial and lateral LMC neurons}

A thorough understanding of RhoGTPase regulation in axon guidance has been challenging, partially due to their involvement in multiple signaling pathways and to functional redundancy in proteins that modulate them (O'Donnell et al., 2009). Ephexin1 is expressed in most LMC neurons and is required for proper axon trajectory of both medial and lateral LMC divisions, suggesting a nonredundant role in LMC axon pathfinding. This raises the question of how ephexin 1 relays guidance signals to the cytoskeleton. As a Rho GEF, ephexin1 can activate RhoA, Rac1, and Cdc42 with no obvious preference in the absence of stimulation, but the phosphorylation of ephexin 1 following stimulation by ephrin-A, for example, potentiates its activity toward RhoA and inhibits Rac1 and Cdc42 activation (Shamah et al., 2001). Several examples of biochemical evidence imply that ephexin1 activity is enhanced in the presence of SFKs during growth-cone collapse events (Knöll and Drescher, 2004; Sahin et al., 2005). Thus, a general model of ephexin1 function in axon guidance could first involve SFKs recruited by the C-terminal domain of a guidance receptor activated by its ligand, followed by phosphorylation of SFK targets, including ephexin1. The activation of ephexin 1 is then required for small GTPase activity result- ing in growth-cone turning, as shown by our observations of misprojecting spinal motor axons in ephexin1 mutants. Indeed, our data showing the attenuation of Src-mediated motor axon redirection by ephexin1 loss or ectopic expression of nonphosphorylatable ephexin1 implicate ephexin1 as a target of SFKs in this context.

Our data indicate that although ephexin 1 is expressed in most LMC neurons, its requirement for the fidelity of LMC axon trajectory selection appears to be differential: medial LMC pathfinding, compared with lateral LMC pathfinding, appears to depend more on ephexin1 function. This differential requirement of ephexin 1 could be due to multiple pathways being required for guidance of either LMC division. Convincing evidence has demonstrated EphA and EphB signaling in guidance of lateral and medial LMC axons, respectively (Kania and Jessell, 2003; Luria et al., 2008). The differential sensitivity of lateral and medial LMC neurons to ephexin 1 could thus reflect the differential requirement of ephexin 1 in EphA and EphB receptor signaling (see next section for more details). Recent findings also suggest netrin-1 as a bifunctional ligand, attracting lateral LMC axons and repelling medial LMC axons (Poliak et al., 2015). There is still no biochemical evidence of netrin-1 receptors (Dcc and Unc5c), c-Ret, or Neuropilin2 association with ephexin1. However, our in vitro data showing no obvious change of LMC neurite growth preference toward netrin-1 stripes in ephexin 1 knockdown suggest a dispensable role of ephexin1 in netrin-1-mediated LMC pathfinding. To thoroughly investigate the involvement of ephexin 1 in other guidance systems in this context, in vitro response to individual cues, such as GDNF or semaphorins, using similar approaches could be measured in cultured motor neurons lacking ephexin1 (Huber et al., 2005; Kramer et al., 2006; Dudanova et al., 2010; Bonanomi et al., 2012).

\section{Ephexin1 function in ephrin:Eph signaling}

Our experiments implicating ephexin1 in EphA signaling are in line with previous findings in retinal ganglion cells and cortical neurons suggesting a potential role of ephexin1 in EphAmediated axon guidance (Shamah et al., 2001; Knöll and Drescher, 2004; Egea et al., 2005). However, no clear evidence so far has demonstrated ephexin1 function in EphB-signaling and EphB-mediated axon guidance events. Indeed, our data showing differential requirement of ephexin1 in Eph-mediated motor axon guidance suggest that ephexin 1 plays an essential role in EphB-mediated medial LMC pathfinding and only a partial role in EphA-mediated lateral LMC pathfinding. Previous work demonstrated that ephexin1 is a target of SFK-dependent tyrosine phosphorylation in Eph signaling (Knöll and Drescher, 2004; Zhang et al., 2007). Combined with previous findings showing the differential requirement of SFKs in Eph-mediated LMC guidance (Kao et al., 2009), our data demonstrating ephexin1 as a potential target of SFKs suggest that ephexin1 functions as an essential intermediary downstream of SFKs to modulate Eph signaling in LMC pathfinding. However, a comparison of our in vitro data showing a dispensable role of ephexin1 in netrin-1mediated LMC axon trajectory selection with recent studies showing Src function in both Eph and netrin-1 signaling in LMC neurons leads us to propose that there are Src targets other than ephexin1 required in other guidance pathways (Poliak et al., 2015). Other effectors, such as the focal adhesion kinase, paxillin, and Nck members, are also implicated in both Eph pathways. Among these effectors, Nck1 and Nck2 are expressed in spinal motor neurons when axons grow into the limb, suggesting that 
they could relay SFK signals in LMC axons (Hall et al., 2001; Bladt et al., 2003; Vindis et al., 2004).

Two reasonable explanations for the partial ephexin1 requirement in lateral LMC neurons are that ephexin1 is only required for the guidance of a lateral LMC subpopulation, or that ephexin1 is redundant with other EphA effectors participating in lateral LMC axon guidance. Other Rho family GEFs, including kalirin and Vav2, are also implicated as Eph effectors: kalirin, like ephexin1, is preferentially required as an EphB but not an EphA effector to modulate cytoskeletal dynamics, but Vav2 can interact with both Eph pathways to modulate growth-cone motility (Penzes et al., 2003; Moeller et al., 2006). Further investigation of Vav2 expression and function in LMC could thus provide a better understanding of either Eph pathway in LMC pathfinding.

\section{Conclusion}

Here, we have shown that ephexin1 is required for motor axon trajectory selection in vivo. This is the first report pointing to an important role of ephexin1 in EphB signaling, and directly comparing its involvement in EphA-regulated versus EphB-regulated motor axon guidance to show a differential requirement of ephexin1 in different Eph pathways in vivo. This thus highlights the importance of the LMC motor axon projection system as a model of a simple axon guidance decision in which the role of receptor signaling relay machinery can be investigated.

\section{References}

Bladt F, Aippersbach E, Gelkop S, Strasser GA, Nash P, Tafuri A, Gertler FB, Pawson T (2003) The murine nck SH2/SH3 adaptors are important for the development of mesoderm-derived embryonic structures and for regulating the cellular actin network. Mol Cell Biol 23:4586-4597. CrossRef Medline

Bonanomi D, Chivatakarn O, Bai G, Abdesselem H, Lettieri K, Marquardt T, Pierchala BA, Pfaff SL (2012) Ret is a multifunctional coreceptor that integrates diffusible- and contact-axon guidance signals. Cell 148:568582. CrossRef Medline

Bülow HE, Boulin T, Hobert O (2004) Differential functions of the C. elegans FGF receptor in axon outgrowth and maintenance of axon position. Neuron 42:367-374. CrossRef Medline

Defourny J, Poirrier AL, Lallemend F, Mateo Sánchez S, Neef J, Vanderhaeghen P, Soriano E, Peuckert C, Kullander K, Fritzsch B, Nguyen L, Moonen G, Moser T, Malgrange B (2013) Ephrin-A5/EphA4 signalling controls specific afferent targeting to cochlear hair cells. Nat Commun 4:1438. CrossRef Medline

Dudanova I, Gatto G, Klein R (2010) GDNF acts as a chemoattractant to support ephrinA-induced repulsion of limb motor axons. Curr Biol 20: 2150-2156. CrossRef Medline

Eberhart J, Swartz ME, Koblar SA, Pasquale EB, Krull CE (2002) EphA4 constitutes a population-specific guidance cue for motor neurons. Dev Biol 247:89-101. CrossRef Medline

Egea J, Nissen UV, Dufour A, Sahin M, Greer P, Kullander K, Mrsic-Flogel TD, Greenberg ME, Kiehn O, Vanderhaeghen P, Klein R (2005) Regulation of EphA kinase activity is required for a subset of axon guidance decisions suggesting a key role for receptor clustering in eph function. Neuron 47:515-528. CrossRef Medline

Frank CA, Pielage J, Davis GW (2009) A presynaptic homeostatic signaling system composed of the eph receptor, ephexi, Cdc42, and CaV2.1 calcium channels. Neuron 61:556-569. CrossRef Medline

Fu WY, Chen Y, Sahin M, Zhao XS, Shi L, Bikoff JB, Lai KO, Yung WH, Fu AK, Greenberg ME, Ip NY (2007) Cdk5 regulates EphA4-mediated dendritic spine retraction through an ephexin1-dependent mechanism. Nat Neurosci 10:67-76. CrossRef Medline

Gallarda BW, Bonanomi D, Müller D, Brown A, Alaynick WA, Andrews SE, Lemke G, Pfaff SL, Marquardt T (2008) Segregation of axial motor and sensory pathways via heterotypic trans-axonal signaling. Science 320: 233-236. CrossRef Medline

Hall C, Michael GJ, Cann N, Ferrari G, Teo M, Jacobs T, Monfries C, Lim L (2001) $\alpha 2$-Chimaerin, a Cdc42/Rac1 regulator, is selectively expressed in the rat embryonic nervous system and is involved in neuritogenesis in N1E-115 neuroblastoma cells. J Neurosci 21:5191-5202. Medline

Hamburger V, Hamilton HL (1951) A series of normal stages in the development of the chick embryo. J Morphol 88:195-272. Medline

Helmbacher F, Schneider-Maunoury S, Topilko P, Tiret L, Charnay P (2000) Targeting of the EphA4 tyrosine kinase receptor affects dorsal/ventral pathfinding of limb motor axons. Development 127:3313-3324. Medline

Huber AB, Kania A, Tran TS, Gu C, De Marco Garcia N, Lieberam I, Johnson D, Jessell TM, Ginty DD, Kolodkin AL (2005) Distinct roles for secreted semaphorin signaling in spinal motor axon guidance. Neuron 48:949964. CrossRef Medline

Kania A, Jessell TM (2003) Topographic motor projections in the limb imposed by LIM homeodomain protein regulation of ephrin-A:EphA interactions. Neuron 38:581-596. CrossRef Medline

Kania A, Johnson RL, Jessell TM (2000) Coordinate roles for LIM homeobox genes in directing the dorsoventral trajectory of motor axons in the vertebrate limb. Cell 102:161-173. CrossRef Medline

Kao TJ, Kania A (2011) Ephrin-mediated cis-attenuation of Eph receptor signaling is essential for spinal motor axon guidance. Neuron 71:76-91. CrossRef Medline

Kao TJ, Palmesino E, Kania A (2009) SRC family kinases are required for limb trajectory selection by spinal motor axons. J Neurosci 29:5690-5700. CrossRef Medline

Kao TJ, Nicholl GC, Johansen JA, Kania A, Beg AA (2015) $\alpha 2$-Chimaerin is required for eph receptor-class-specific spinal motor axon guidance and coordinate activation of antagonistic muscles. J Neurosci 35:2344-2357. CrossRef Medline

Knöll B, Drescher U (2004) Src family kinases are involved in EphA receptor-mediated retinal axon guidance. J Neurosci 24:6248-6257. CrossRef Medline

Knöll B, Weinl C, Nordheim A, Bonhoeffer F (2007) Stripe assay to examine axonal guidance and cell migration. Nat Protoc 2:1216-1224. CrossRef Medline

Kramer ER, Knott L, Su F, Dessaud E, Krull CE, Helmbacher F, Klein R (2006) Cooperation between GDNF/Ret and ephrinA/EphA4 signals for motor-axon pathway selection in the limb. Neuron 50:35-47. CrossRef Medline

Lance-Jones C, Landmesser L (1981) Pathway selection by embryonic chick motoneurons in an experimentally altered environment. Proc R Soc Lond B Biol Sci 214:19-52. CrossRef Medline

Landmesser L (1978) The development of motor projection patterns in the chick hind limb. J Physiol 284:391-414. CrossRef Medline

Luria V, Krawchuk D, Jessell TM, Laufer E, Kania A (2008) Specification of motor axon trajectory by ephrin-B:EphB signaling: symmetrical control of axonal patterning in the developing limb. Neuron 60:1039-1053. CrossRef Medline

Moeller ML, Shi Y, Reichardt LF, Ethell IM (2006) EphB receptors regulate dendritic spine morphogenesis through the recruitment/phosphorylation of focal adhesion kinase and RhoA activation. J Biol Chem 281:15871598. CrossRef Medline

Momose T, Tonegawa A, Takeuchi J, Ogawa H, Umesono K, Yasuda K (1999) Efficient targeting of gene expression in chick embryos by microelectroporation. Dev Growth Differ 41:335-344. CrossRef Medline

O’Donnell M, Chance RK, Bashaw GJ (2009) Axon growth and guidance: receptor regulation and signal transduction. Annu Rev Neurosci 32:383412. CrossRef Medline

Penzes P, Beeser A, Chernoff J, Schiller MR, Eipper BA, Mains RE, Huganir RL (2003) Rapid induction of dendritic spine morphogenesis by transsynaptic EphrinB-EphB receptor activation of the rho-GEF kalirin. Neuron 37:263-274. CrossRef Medline

Poliak S, Morales D, Croteau LP, Krawchuk D, Palmesino E, Morton S, Cloutier JF, Charron F, Dalva MB, Ackerman SL, Kao TJ, Kania A (2015) Synergistic integration of Netrin and ephrin axon guidance signals by spinal motor neurons. eLife 4:e10841. CrossRef Medline

Ponimaskin E, Dityateva G, Ruonala MO, Fukata M, Fukata Y, Kobe F, Wouters FS, Delling M, Bredt DS, Schachner M, Dityatev A (2008) Fibroblast growth factor-regulated palmitoylation of the neural cell adhesion molecule determines neuronal morphogenesis. J Neurosci 28:8897-8907. CrossRef Medline

Rozen S, Skaletsky H (2000) Primer3 on the WWW for general users and for biologist programmers. Methods Mol Biol 132:365-386. Medline

Sahin M, Greer PL, Lin MZ, Poucher H, Eberhart J, Schmidt S, Wright TM, 
Shamah SM, O'connell S, Cowan CW, Hu L, Goldberg JL, Debant A, Corfas G, Krull CE, Greenberg ME (2005) Eph-dependent tyrosine phosphorylation of ephexin 1 modulates growth cone collapse. Neuron 46:191-204. CrossRef Medline

Schaeren-Wiemers N, Gerfin-Moser A (1993) A single protocol to detect transcripts of various types and expression levels in neural tissue and cultured cells: in situ hybridization using digoxigenin-labelled cRNA probes. Histochemistry 100:431-440. CrossRef Medline

Shamah SM, Lin MZ, Goldberg JL, Estrach S, Sahin M, Hu L, Bazalakova M, Neve RL, Corfas G, Debant A, Greenberg ME (2001) EphA receptors regulate growth cone dynamics through the novel guanine nucleotide exchange factor ephexin. Cell 105:233-244. CrossRef Medline

Shi L, Butt B, Ip FC, Dai Y, Jiang L, Yung WH, Greenberg ME, Fu AK, Ip NY (2010) Ephexin1 is required for structural maturation and neurotransmission at the neuromuscular junction. Neuron 65:204-216. CrossRef Medline

Shirasaki R, Lewcock JW, Lettieri K, Pfaff SL (2006) FGF as a target-derived chemoattractant for developing motor axons genetically programmed by the LIM code. Neuron 50:841-853. CrossRef Medline

Tosney KW, Landmesser LT (1985) Development of the major pathways for neurite outgrowth in the chick hindlimb. Dev Biol 109:193-214. CrossRef Medline

Tsuchida T, Ensini M, Morton SB, Baldassare M, Edlund T, Jessell TM, Pfaff SL (1994) Topographic organization of embryonic motor neurons defined by expression of LIM homeobox genes. Cell 79:957-970. CrossRef Medline

Vindis C, Teli T, Cerretti DP, Turner CE, Huynh-Do U (2004) EphB1mediated cell migration requires the phosphorylation of paxillin at tyr31/Tyr-118. J Biol Chem 279:27965-27970. CrossRef Medline

Wang G, Scott SA (2000) The "waiting period" of sensory and motor axons in early chick hindlimb: its role in axon pathfinding and neuronal maturation. J Neurosci 20:5358-5366. Medline

Zhang Y, Sawada T, Jing X, Yokote H, Yan X, Sakaguchi K (2007) Regulation of ephexin1, a guanine nucleotide exchange factor of rho family GTPases, by fibroblast growth factor receptor-mediated tyrosine phosphorylation. J Biol Chem 282:31103-31112. CrossRef Medline

Zhou L, Martinez SJ, Haber M, Jones EV, Bouvier D, Doucet G, Corera AT, Fon EA, Zisch AH, Murai KK (2007) EphA4 signaling regulates phospholipase $\mathrm{C} 1$ activation, cofilin membrane association, and dendritic spine morphology. J Neurosci 27:5127-5138. CrossRef Medline 